\title{
An extension of valid syllogisms to valid categorical arguments
}

\author{
To the memory of my sister Cristina Popa, 1948-2018.
}

\section{DAN CONSTANTIN RADULESCU}

\begin{abstract}
One presents the Set Theory Model (STM) of the valid categorical arguments (VCAs) as an improvement on the Classic Categorical Syllogistic (CCS) approach to the valid (categorical) syllogisms (VS) - a proper subset of the VCAs. The STM was initially developed by George Boole and Lewis Carroll, who worked with a "universe of discourse", $U$, which contains the pairwise complementary sets, or categorical terms, $S, S^{\prime}($ non$S), P, P^{\prime}($ non- $P), M, M^{\prime}($ non- $M)$, and is thus partitioned into 8 subsets: $S P M:=S \cap P \cap M$, $S^{\prime} P M, \ldots, S^{\prime} P^{\prime} M^{\prime}$. In $S T M$ both the positive terms, $S, P, M$, and the negative terms, $S^{\prime}, P^{\prime}, M^{\prime}$, are allowed to appear in the pairs of categorical premises (PCPs) and their entailed logical consequences (LCs). One thus counts 64 distinct PCPs, out of which only 32 PCPs generate $V C A s$, and 32 PCPs do not entail any LC. By comparison, CCS admits PCPs worded only via the positive terms $S, P, M$, and accepts as VS LCs only the statements $E(S, P), I(S, P)$, $A(S, P)$, or $O(S, P)$. It is easier to see on the VCA set, than on its VS proper subset, that there are only three distinct types of VCAs, (and of VS), and that all the VCAs of the same type are equivalent modulo the term relabelings $p:=P \leftrightarrow P^{\prime}, \quad s:=S \leftrightarrow S^{\prime}, \quad m:=M \leftrightarrow M^{\prime}$ and their compositions. Besides the VCAs and their LCs, one discusses "VCA sorites", "VCA distribution conservation", empty set constraints (ESC), and "VCA generalized versions" of the Rules of Valid Syllogisms (RofVS).
\end{abstract}

Keywords: categorical syllogisms $\bullet$ categorical premises $\bullet$ Karnaugh map $\bullet$ valid categorical argument $\bullet$ set relabelings $\bullet$ set theory model of categorical syllogisms $\bullet$ valid syllogism

\section{Introduction}

As George Boole and Lewis Carroll noticed, any LC of a VCA pinpoints to just one and only one of the eight subsets partitioning $U$, and asserts one of the following: one subset remains possibly non empty but the other three subsets are empty, out of the four subsets partitioning either one of the sets $\mathrm{S}, \mathrm{P}, \mathrm{S}^{\prime}, \mathrm{P}^{\prime}$ - this type of LC is entailed by the Barbara type (1) PCPs - they contain two universal premises which empty four subsets of both $\mathrm{M}$ and $\mathrm{M}$; one subset remains possibly non empty but the other three subsets are empty, out of the four subsets partitioning either M or $\mathrm{M}^{\prime}$ - this type of LC is entailed by the Darapti type (2) PCPs - they contain two universal premises, emptying three subsets of either M or M'; one subset out of eight is definitely not empty - this type of LC is entailed by Darii/Datisi subtype (3a) PCPs, or by Disamis/Dimaris subtype (3b) PCPs - they contain one universal, plus one particular premise, emptying subsets of, and placing set elements in, either $\mathrm{M}$ or M'. Besides the three PCP types that generate VCAs, there are two more PCP types which do not entail any LCs: one type is made of two particular premises, and the other type is made of a universal premise emptying subsets of M, plus a particular premise placing set elements in subsets of M' (or the other way around). Any LC of such premises amounts to just repeating one or both premises - these PCPs are uninteresting, except for counting how many such PCPs do exist. 
The Classic Categorical Syllogistic (CCS) uses syllogistic figures, which amounts to counting the statements $\mathrm{E}(\mathrm{x}, \mathrm{y}):=$ No $\mathrm{x}$ is $\mathrm{y}$, and $\mathrm{E}(\mathrm{y}, \mathrm{x}):=$ No $\mathrm{y}$ is $\mathrm{x}$, $(\operatorname{resp} . \mathrm{I}(\mathrm{x}, \mathrm{y}):=$ Some $\mathrm{x}$ is $\mathrm{y}$, and $\mathrm{I}(\mathrm{y}, \mathrm{x}):=$ Some $\mathrm{y}$ is $\mathrm{x}$ ), as being distinct; this leads to 64 "apparently distinct" PCPs formulable via positive terms only 16 statement pairs, $\mathrm{AA}, \mathrm{AE}, \mathrm{AI}, \mathrm{AO}, \ldots \mathrm{OO}$, each generating 4 distinct figures (except that, in fact, $\mathrm{E}(\mathrm{x}, \mathrm{y})=\mathrm{E}(\mathrm{y}, \mathrm{x})$ and $\mathrm{I}(\mathrm{x}, \mathrm{y})=\mathrm{I}(\mathrm{y}, \mathrm{x}))$. By convention, adopted by both CCS and STM, P and M appear in the firstly listed (P-)premise; S and M (again), appear in the secondly listed (S-)premise. The disregard of superfluous figure information, and not supposing that universal premises entail existential import (ei), can be viewed as a (restricted) "Boolean point of view", Hurley, 272-280. But the "complete Boolean point of view" is put forth by the STM: all terms are interpreted as sets, the PCPs, and LCs, contain both positive and negative terms, there are three "LC entailing" PCP types, which thus generate three VCA types, and all the VCAs of the same type are equivalent. When - as in CCS - only positive terms are used in the PCPs, then, there are only six distinct P-premises, (resp. Spremises), only 36 distinct PCPs, and seven possible LCs, (out of which just the first four are accepted as VS LCs): $A(S, P), E(S, P), I(S, P), O(S, P), A(P, S), O(P, S), I\left(S^{\prime}, P^{\prime}\right)$. In STM all VCAs are treated on an equal footing, while CCS has to "dispose" of VCAs whose LCs are A(P,S), O(P,S), or I( $\left(\mathrm{S}^{\prime}, \mathrm{P}^{\prime}\right)$ ), since for CCS the choice is VS or nothing - there are no recognized VCAs in CCS but the VS. Cf. the (restricted) Boolean point of view, only 8 PCPs out of the 36, generate non-ei VS, (Barbara, Celarent/Cesare, Camestres/ Camenes, Bocardo, Disamis/Dimaris, Darii/Datisi, Ferio/Festino/Ferison/ Fresison and Baroco), three PCPs generate ei VS for which a VS with the same PCP but a universal LC does not exist, (Bramantip - obtained via ei on P, and Darapti, Felapton/ Fesapo - obtained via ei on M), and three PCPs of type (1) - out of the above listed eight - generate ei VS for which a VS with the same PCP but a universal LC does exist, (Barbari, Celaront/Cesaro, Camestros/ Camenos obtained via ei on S). If, instead of the restricted Boolean point of view, one uses syllogistic figures, then all the above names specify distinct VS: 15 (non-ei) VS, 4 ei VS for which a VS with the same PCP but a universal LC does not exist, and, resp., 5 ei VS for which a VS with the same PCP but a universal LC does exist, for a total of 24 VS and ei VS. STM argues that discussing VCAs is the natural thing to do, while restricting the VCA set to the VS is contrived, (or is a CCS' weakness). As Carroll 1986, p.250, puts it: "...the ordinary textbooks of Formal Logic have elaborately discussed no less than nineteen different forms of Syllogisms - each with its own special and exasperating Rules, while the whole constitutes an almost useless machine, for practical purposes, many of of the Conclusions being incomplete, and many quite legitimate forms being ignored", "As to syllogisms, I find that their nineteen forms, with about a score of others which the textbooks have ignored, can all be arranged under three forms, each with a very simple Rule of its own". (To get to Carroll's mentioned 19 forms, one adds to the 15 VS cited above, the four ei VS, Bramantip, Darapti, Felapton and Fesapo, for which a (non-ei) VS with a universal LC does not exist.) Carroll 1986, p.240 or Carroll, 1958, p.173, gives three concrete examples of VCAs containing negative terms, and asserts that "The theory that two negative premises prove nothing" is "another craze of 'The Logicians', fully as morbid as their dread of a negative Attribute" (i.e., negative terms S',P',M'). Boole's and Carroll's three types of VCAs, and the algebraic method of finding LCs, based on Carroll's method of subscripts, are described in this Section, while, moreover, the number of distinct PCPs is increased from 36 to 64 by allowing negative terms in the PCPs - which also adds VCAs whose LC is E( $\left.\mathrm{S}^{\prime}, \mathrm{P}^{\prime}\right)$, and brings up to eight the total number of LCs that the VCAs may have (after the middle term $\mathrm{M}$ is eliminated from the LCs): $\mathrm{E}\left(\mathrm{S}^{*}, \mathrm{P}^{*}\right), \mathrm{I}\left(\mathrm{S}^{*}, \mathrm{P}^{*}\right)$, where $\mathrm{S}^{*} \in\left\{\mathrm{S}, \mathrm{S}^{\prime}\right\}, \mathrm{P}^{*} \in\left\{\mathrm{P}, \mathrm{P}^{\prime}\right\} ; 32$ out of the 64 PCPs generate a total of 40 (non-ei) VCAs and 24 ei VCAs, and 32 PCPs do not entail any LC; see below.

One discusses three methods of finding the LCs of each VCA type; this sheds some new light on the VS subset, too. Based on representing any particular premise as a non-empty set intersection, and of its contradictory universal premise as the emptying of the same set intersection, one presents two 
methods of finding the LCs: an "algebraic", tree like, method, (practically the same as Carroll's method of subscripts), and a graphical method based on a Karnaugh map of the subsets of U. A third "LC finding method" is based on a "slightly modified Euler diagram": as in the other two methods, any particular premise is represented as a non-empty set intersection, while any universal premise is represented not as an empty set intersection, but as a set inclusion of adeptly chosen sets, such that all PCPs from each of the three VCA types comport with the same type of graph. The usual 3-circle Venn diagram representation of S,P,M, see Quine, or Hurley (272-280), and the usual mood and figure CCS classification of the VS, do not illuminate the fact that the VS are of three types, too, and that the VS of the same type are equivalent: each VS, (resp. each VCA), can be reformulated as any other VS, (resp. as any other VCA), of the same type. Using modified Euler diagrams, e.g., O(P,M)= "Some P is not $\mathrm{M}$ " is represented as two intersecting circles corresponding to $\mathrm{P} \cap \mathrm{M} \prime \varnothing \varnothing$; this also shows that even if $\mathrm{O}(\mathrm{P}, \mathrm{M})$ is formulable using only the positive terms $\mathrm{P}$ and $\mathrm{M}$, in fact $\mathrm{O}(\mathrm{P}, \mathrm{M})$ "acts" on $\mathrm{M}$ ', since it lays set elements in the intersection $\mathrm{P} \cap \mathrm{M}^{\prime}=: \mathrm{PM}$ '. One represents $\mathrm{A}(\mathrm{M}, \mathrm{P})$ as an $\mathrm{M}$-circle included in the P-circle, and $\mathrm{A}(\mathrm{P}, \mathrm{M})$ as either a $\mathrm{P}$-circle included in the M-circle, or, equivalently, by contraposition, as an $\mathrm{M}^{\prime}$-circle included in the $\mathrm{P}^{\prime}$-circle, (in accord also to the fact that $\mathrm{A}(\mathrm{P}, \mathrm{M})$ means $\mathrm{P} \cap \mathrm{M}^{\prime}=: \mathrm{PM}^{\prime}=\varnothing$, i.e., $\mathrm{A}(\mathrm{P}, \mathrm{M})$, acts on $\mathrm{M}^{\prime}$ by emptying the $\mathrm{PM}^{\prime}$ intersection; moreover $\mathrm{P}^{\prime}$ is the largest part of $U$ which does not intersect $P$ - thus $\mathrm{M}^{\prime} \subseteq \mathrm{P}^{\prime}$. The $\mathrm{E}(\mathrm{M}, \mathrm{P})$ statement is represented in the first two methods as $\mathrm{MP}=\varnothing$, while in the modified Euler diagram is represented as either an M-circle included in the $\mathrm{P}^{\prime}$-circle, or, as a P-circle included in the $\mathrm{M}^{\prime}$-circle. One easily finds that the graphical patterns generated by the modified Euler diagram method are as follows: any type (1) PCP can be graphed as a double inclusion with $\mathrm{M}$, (or $\mathrm{M}^{\prime}$ ), in the middle, $\alpha \subseteq \mathrm{M}^{*} \subseteq \beta$, where $\alpha$ and $\beta$ are two different letters chosen from the possible "end terms" $\left\{S, S^{\prime}, P, P^{\prime}\right\}$, where $M^{*} \in\left\{M, M^{\prime}\right\}$, and the LC can be written as an equality $\alpha=\alpha \cap M^{*} \cap \beta=: \alpha M^{*} \beta$, or, All $\alpha$ is $\beta$ - after the middle term $M^{*}$ is eliminated; any type (2) PCP can be graphed as $M^{*} \subseteq \alpha, M^{*} \subseteq \beta$, where the LC, again, can be written as an equality $M^{*}=M^{*} \alpha \beta$ or All $\mathrm{M}^{*}$ is $\alpha \cap \beta=: \alpha \beta$, or, $\mathrm{I}(\alpha, \beta)$, after the ei condition, $\mathrm{M}^{*} \neq \varnothing$, is imposed; any type (3) PCP can be graphed as $M^{*} \cap \alpha=: \alpha M^{*} \neq \varnothing, M^{*} \subseteq \beta$, where the LC can now be expressed as an "inequality" $\alpha M^{*} \beta \neq \varnothing$, or, Some $\alpha$ is $\beta$ - after the middle term $M^{*}$ is, again, eliminated. Note that the precise LC always contains $\mathrm{M}$ (or $\mathrm{M}^{\prime}$ ). Note that the set of inclusions characteristic for each VCA type also gives the recipe for finding the LC: for types (1) and (2) write the LC as an equality for the set appearing on the left side of the inclusions, and, on the right hand side of the equality, add, going from left to right, a new letter/set for each inclusion in the set of inclusions, giving the LCs, $\alpha=\alpha \mathrm{M}^{*} \beta$, and resp., $M^{*}=M^{*} \alpha \beta$. The three VCA types can be generalized to sorites, (see Section 4 ), whereby the corresponding inclusions and LCs will be:

Type (1) $\alpha \subseteq M_{1} \subseteq M_{2} \subseteq M_{3} \subseteq . . \subseteq M_{n} \subseteq \beta$; with the LC $\alpha=\alpha M_{1} M_{2} M_{3} \ldots M_{n} \beta$. Notice that the first chain of inclusions is equivalent with this second chain: $\beta^{\prime} \subseteq \mathrm{M}_{\mathrm{n}}{ }^{\prime} \subseteq \mathrm{M}_{\mathrm{n}-1}{ }^{\prime} \subseteq \mathrm{M}_{\mathrm{n}-2}{ }^{\prime} \subseteq . . \subseteq \mathrm{M}_{1}{ }^{\prime} \subseteq \alpha^{\prime}$, whose $\mathrm{LC}$ is $\beta^{\prime}=\alpha^{\prime} \mathrm{M}_{1}{ }^{\prime} \mathrm{M}_{2}{ }^{\prime} \mathrm{M}_{3}{ }^{\prime} \ldots \mathrm{M}_{\mathrm{n}}{ }^{\prime} \beta^{\prime}$. Obviously, $\alpha \neq \beta^{\prime}$, and $\mathrm{A}(\alpha, \beta)=\mathrm{A}\left(\beta^{\prime}, \alpha^{\prime}\right)$.

Type (2) $M \subseteq \alpha, M \subseteq M_{1}, M \subseteq M_{2}, M \subseteq M_{3}, \ldots, M \subseteq M_{n}, M \subseteq \beta$; with the $L C M=M \alpha M_{1} M_{2} M_{3} \ldots M_{n} \beta$ Type (3) $\mathrm{M} \cap \alpha=: \mathrm{M} \alpha \neq \varnothing, \mathrm{M} \subseteq \mathrm{M}_{1}, \mathrm{M} \subseteq \mathrm{M}_{2}, \mathrm{M} \subseteq \mathrm{M}_{3}, \ldots, \mathrm{M} \subseteq \mathrm{M}_{\mathrm{n}}, \alpha \subseteq \alpha_{1}, \alpha \subseteq \alpha_{2}, \alpha \subseteq \alpha_{3}, \ldots, \alpha \subseteq \alpha_{\mathrm{r}}$; with the LC $M \alpha M_{1} M_{2} M_{3} \ldots M_{n} \alpha_{1} \alpha_{2} \alpha_{3}, \ldots, \alpha_{r} \neq \varnothing$. If the sets appearing in each VCA type, together with their complementary sets in the universal set $U$, generate a partition of $U$, then each LC defines, or pinpoints to, a unique subset from that partition of U. Slightly more generalized sorites, (they include "Darapti decorations"), are presented in Section 4.

By contrast, the 3-circle Venn diagram, represents any PCP by the same 3 circles without any PCP type differentiation or LC insight - except that if the 3-circle graph of the PCP validates the proposed LC, then the LC is considered (graphically) proven. The fact that the modified Euler diagram style of graphing, and the grouping of graphs by PCP types are adequate, will become even clearer after one discusses the equivalent graphical patterns highlighted by the algebraic and Karnaugh map methods of 
finding the LC(s) of any VCA.

As noticed, the universal set $U$ contains the $\mathrm{S}, \mathrm{P}, \mathrm{M}$ sets, and also contains $\mathrm{S}^{\prime}, \mathrm{P}^{\prime}, \mathrm{M}^{\prime}$ - the complements in $\mathrm{U}$ of $\mathrm{S}, \mathrm{P}, \mathrm{M}$ - which partitions $\mathrm{U}$ into 8 subsets. Obviously, each of the $\mathrm{S}, \mathrm{P}, \mathrm{M}, \mathrm{S}^{\prime}, \mathrm{P}^{\prime}, \mathrm{M}^{\prime}$ sets is partitioned only into 4 subsets out of the 8 subsets of U.

As mentioned, there are six distinct P-premises, (resp. S-premises), worded using only the "positive" terms M,P, (resp. M,S) and the A,E,I,O statements/quantifiers. Thus a "PCP matrix", with P-premises listed firstly - as rows, and S-premises listed secondly - as columns, has 36 distinct PCPs, even if, by using syllogistic figures, one initially overcounts 64 PCPs as being distinct. The conversions used in the direct reduction to the First (syllogistic) Figure reflect this overcount, but one ends up, e.g., with four different names, Ferio, Festino, Ferison, Fresison, for the same PCP/syllogism. One may say that STM more adeptly models the content of the A,E,I,O statements than the syllogistic figures. Besides using Figures, CCS is characterized by the admission of only positive terms, (i.e., S,P,M), in both PCPs and LCs, and by accepting as LCs of the VS only the statements A(S,P), E(S,P), I(S,P), O(S,P). This requires that the $\mathrm{P}$ term be truly the predicate of the LC. The convention, adopted by both STM and CCS, is to firstly list the premise which contains the term denoted by $\mathrm{P}$, (or more generally $\mathrm{P}^{\prime}$ which STM allows, but CCS does not).

By removing the CCS "positive terms only" restriction, i.e., allowing all the S,P,M,S',P',M' terms to appear in the premises, (and in the LCs), and by using conversions and obversions, (which CCS recognizes as valid), one can write the resulting eight distinct P-premises as follows: $\mathrm{E}\left(\mathrm{M}^{*}, \mathrm{P}^{*}\right)$ will denote the 4 universal P-premises, and $\mathrm{I}\left(\mathrm{M}^{*}, \mathrm{P}^{*}\right)$ will denote the 4 particular P-premises. Similarly, one gets eight $\mathrm{S}$-premises, $\mathrm{E}\left(\mathrm{M}^{*}, \mathrm{~S}^{*}\right), \mathrm{I}\left(\mathrm{M}^{*}, \mathrm{~S}^{*}\right)$, where $\mathrm{M}^{*} \in\left\{\mathrm{M}, \mathrm{M}^{\prime}\right\}, \mathrm{P}^{*} \in\left\{\mathrm{P}, \mathrm{P}^{\prime}\right\}, \mathrm{S}^{*} \in\left\{\mathrm{S}, \mathrm{S}^{\prime}\right\}$. For example, $\mathrm{E}\left(\mathrm{M}^{\prime}, \mathrm{P}^{\prime}\right)=: \mathrm{A}^{\prime}$, meaning $\mathrm{All} \mathrm{M}^{\prime}$ is $\mathrm{P}$, and, $\mathrm{I}\left(\mathrm{M}^{\prime}, \mathrm{P}^{\prime}\right)=: \mathrm{O}^{\prime}$, meaning Some $\mathrm{M}^{\prime}$ is not $\mathrm{P}$, are the two extra premises added to the six P-premises formulable using only positive terms. Note that the other two P-premises "acting on", (i.e., containing - when expressed via E or I statements), M', but still formulable via only positive terms are $A(P, M)=E\left(M^{\prime}, P\right)=: E^{\prime}$, and $O(P, M)=I\left(M^{\prime}, P\right)=: I^{\prime}$. This way one gets four P-premises, E,A,I,O, “acting on" M, and four P-premises, E',A',I',O', acting on M', for a total of eight distinct P-premises. This new notation plus the convention of firstly listing the Ppremise, allows for a 2-letter shorthand writing of the PCPs: for example A'A means A(M',P)A(M,S) $=\mathrm{E}\left(\mathrm{M}^{\prime}, \mathrm{P}^{\prime}\right) \mathrm{E}\left(\mathrm{M}, \mathrm{S}^{\prime}\right)$; AI are Darii's premises, and E'I' are Baroco's premises. Note that A,E,I,O form a square of opposition containing $\mathrm{M}$ and $\mathrm{P}$, and $\mathrm{A}^{\prime}, \mathrm{E}^{\prime}, \mathrm{I}^{\prime}, \mathrm{O}^{\prime}$ form another square of opposition containing $\mathrm{M}^{\prime}$ and $\mathrm{P}$. Together, one may say, they form a cube of opposition, with, e.g., the universal statements A,E,E',A' on the top face of the cube. Similarly there are eight distinct S-premises which form another cube of opposition. Pairing a P-premise from the "P-cube" with an S-premise from the "S-cube" one gets now 64 distinct PCPs. As said, by convention, the P-premise will always be listed firstly. One may also ask if one can find multiple VCAs which are simultaneously sound, while taking into account that, e.g., A(M,P) and E(M,P), if both true, as P-premises in two different VCAs, would imply $\mathrm{M}$ being empty, $\mathrm{M}=\varnothing$. Other relationships implied by the other five possible combinations of two universal P-premises being simultaneously true: $E \& E^{\prime}$ imply $P=\varnothing, A^{\prime} \& E^{\prime}$ imply $M^{\prime}=\varnothing, A \& A^{\prime}$ imply $\mathrm{P}^{\prime}=\varnothing, \mathrm{A} \& \mathrm{E}^{\prime}$ imply $\mathrm{P}=\mathrm{M}, \mathrm{A}^{\prime} \& \mathrm{E}$ imply $\mathrm{P}=\mathrm{M}^{\prime}$, and similar relationships hold for the top face of the S-cube. This shows, e.g., that Barbara, AE', and Camestres, E'E, can both be sound, but uninteresting, since in that universal set, $\mathrm{P}=\mathrm{M}$ and $\mathrm{S}=\varnothing$. (More about ESC in Section 5.) As mentioned, in STM, the task of finding if a PCP entails an LC, or not, was already solved by George Boole and Lewis Carroll: there are three types of PCPs, such that each PCP entails at least one LC, and another two PCP types, each type containing 16 PCPs, which do not entail any LC. These latter two types contain the following PCPs: I(M*,P*)I(M*,S*) and I(M*,P*) I(M*',S*) - they are the PCPs made of two particular premises, and, E(M*, $\left.\mathrm{P}^{*}\right) \mathrm{I}\left(\mathrm{M}^{* 1}, \mathrm{~S}^{*}\right)$ and $\mathrm{I}\left(\mathrm{M}^{*}, \mathrm{P}^{*}\right) \mathrm{E}\left(\mathrm{M}^{* 1}, \mathrm{~S}^{*}\right)$ - 
i.e., the PCPs made of one universal and one particular premises, acting one on $\mathrm{M}$ and the other on $M^{\prime}$. (Note that $M^{* \prime}=M$ if $M^{*}=M^{\prime}$, etc.)

Each of the eight type (1), (or type Barbara), E(M*, $\left.\mathrm{P}^{*}\right) \mathrm{E}\left(\mathrm{M}^{*}, \mathrm{~S}^{*}\right), \mathrm{PCP}$, entails two, nonindependent LCs - since these PCPs are in fact "chain inclusion" sorites with just one middle term. By handling these PCPs using a tree like method, (very similar to Lewis Carroll's method of subscripts), and reading the sorite in the Aristotelian way, i.e. starting with the $\mathrm{S}^{*}$ term of the PCP, one gets: $S^{*}=S^{*} M^{*}+S^{*} M^{* \prime}=S^{*} M^{*}=S^{*} M^{*} \mathrm{P}^{*}+\mathrm{S}^{*} \mathrm{M}^{*} \mathrm{P}^{* \prime}=\mathrm{S}^{*} \mathrm{M}^{*} \mathrm{P}^{* \prime}$, where $\mathrm{S}^{*} \mathrm{M}^{*} \mathrm{P}^{* 1}:=$ $\mathrm{M}^{*} \cap \mathrm{S}^{*} \cap \mathrm{P}^{* 1}$, etc., and the + sign denotes union of disjoint sets. Reading the sorite in the Goclenian way, i.e. starting with the $\mathrm{P}^{*}$ term of the PCP, one gets the $2^{\text {nd }} \mathrm{LC}: \mathrm{P}^{*}=\mathrm{P}^{*} \mathrm{M}^{*}+\mathrm{P}^{*} \mathrm{M}^{* \prime}=\mathrm{P}^{*} \mathrm{M}^{* \prime}=$ $\mathrm{P}^{*} \mathrm{M}^{*} \mathrm{~S}^{*}+\mathrm{P}^{*} \mathrm{M}^{*} \mathrm{~S}^{* \prime}=\mathrm{P}^{*} \mathrm{M}^{*} \mathrm{~S}^{*}$. Note that, based on the double inclusions $\mathrm{S} \subseteq \mathrm{M}^{*} \subseteq \mathrm{P}^{\prime}$ and $\mathrm{P}^{*} \subseteq \mathrm{M}^{*} \subseteq \mathrm{S}^{\prime}$ - inferred from the premises $\mathrm{E}\left(\mathrm{M}^{*}, \mathrm{P}^{*}\right) \mathrm{E}\left(\mathrm{M}^{* \prime}, \mathrm{S}^{*}\right)$ - each LC implies the other, i.e., only one LC is independent.

It is even easier to find the LC of the eight type (2), or type Darapti, PCPs, E(M*,P*) E(M*, $\left.\mathrm{S}^{*}\right)$. They entail just one $\mathrm{LC}: \mathrm{M}^{*}=\mathrm{M}^{*} \mathrm{P}^{*}+\mathrm{M}^{*} \mathrm{P}^{* \prime}=\mathrm{M}^{*} \mathrm{P}^{* \prime}=\mathrm{M}^{*} \mathrm{P}^{* \prime} \mathrm{S}^{*}+\mathrm{M}^{*} \mathrm{P}^{* \prime} \mathrm{S}^{* \prime}=\mathrm{M}^{*} \mathrm{P}^{*} \mathrm{~S}^{* \prime}$, which reflects the inclusions $\mathrm{M}^{*} \subseteq \mathrm{P}^{* 1}$ and $\mathrm{M}^{*} \subseteq \mathrm{S}^{* 1}$ asserted by the premises. Thus the middle term is very much part of the LC; it can be eliminated only via ei on $\mathrm{M}^{*}$. Aristotle's definition, (Striker 2009: p.20), "A syllogism is an argument in which, certain things being posited, something other than what was laid down results by necessity because these things are so", provides a justification, (or a pretext), for the elimination of the middle term from the LC. But this elimination always weakens the LC, which instead of asserting something about a unique subset of $U$, will now assert the same thing, less precisely, about two subsets of $U$ - namely that they might be non-empty or that at least one of them is definitely non-empty. Moreover, the contradictory statement of the weakened LC is stronger, (since it refers to a lesser number of sets), than the contradictory statement of the initial, stronger LC. Thus the usual indirect reduction, (or, impossibility, or, reductio ad absurdum), proofs of validity prove weakened LCs using stronger than necessary premises. For example, Darii may be proved, by impossibility, from Camestres. But this is unnecessary: suppose, by impossibility, that Darii's LC, $\mathrm{SPM} \neq \varnothing$, is false, i.e., $\mathrm{SPM}=\varnothing$. Then, also using Darii's general premise, $\mathrm{MP}^{\prime}=\varnothing$, it results $\mathrm{SM}=\mathrm{SMP}+\mathrm{SMP}^{\prime}=\varnothing$, which already contradicts Darii's particular premise, $\mathrm{SM} \neq \varnothing-$ no Camestres had to be invoked, and there is no need to suppose $\mathrm{SP}=\varnothing$, (the contradictory of Darii's weakened LC $\mathrm{SP} \neq \varnothing$ ), since supposing, by impossibility, that $\mathrm{SPM}=\varnothing$ suffices. See also Section 3. If, in a Darapti type PCP, one chooses $\mathrm{M}^{*}=\mathrm{M}, \mathrm{P}^{*}=\mathrm{P}^{\prime}, \mathrm{S}^{*}=\mathrm{S}^{\prime}$ and $\mathrm{M} \neq \varnothing$ one obtains the PCP and the ei LC, I(S,P), of the ei VS Darapti. But if one chooses $\mathrm{M}^{*}=\mathrm{M}, \mathrm{P}^{*}=\mathrm{P}, \mathrm{S}^{*}=\mathrm{S}$ and $\mathrm{M} \neq \varnothing$, then the PCP, E(M,P) E(M,S), contradicts the RofVS - two negative premises are not allowed - and its ei LC, I( $\left.\mathrm{S}^{\prime}, \mathrm{P}^{\prime}\right)$, is not among the four ei VS LCs admitted by the CCS. Nevertheless E(M,P)E(M,S): M=MS'P' is a VCA, (with the LC completely specified after the column sign), and $\mathrm{E}(\mathrm{M}, \mathrm{P}) \mathrm{E}(\mathrm{M}, \mathrm{S})$ : $\mathrm{I}\left(\mathrm{S}^{\prime}, \mathrm{P}^{\prime}\right), \mathrm{M} \neq \varnothing$ is an ei VCA. Similarly, the VCA, E'E':=E(M',P) E(M',S)=A(P,M)A(S,M): $M^{\prime}=M^{\prime} S^{\prime} P^{\prime}$, does not satisfy the RofVS, "the middle term has to be distributed in at least one premise", or, equivalently, its LC and ei LC, $\mathrm{I}\left(\mathrm{S}^{\prime}, \mathrm{P}^{\prime}\right), \mathrm{M} \neq \varnothing$, fail to be one of the four admitted VS LCs. Thus one may say that the role of the two RofVS which refer to PCPs only, is to reject the four PCPs, E'E', EE, OE, EO, whose LC, (or ei LC), is $\mathrm{I}\left(\mathrm{S}^{\prime}, \mathrm{P}^{\prime}\right)$. Notice also that the only difference between Darapti's PCP and the EE or E'E' PCPs consists in choosing if $\mathrm{P}^{*}$ is denoted by $\mathrm{P}$ or $\mathrm{P}^{\prime}$, and similarly for $\mathrm{S}^{*}$ and $\mathrm{M}^{*}$. The "perspicuous" choices are a matter of language not of logic: this shows that all the VCA of the same (sub)type are logically equivalent. Note also that after ei is imposed on any of the S, S',P,P', M, M' sets left with only one possible non-empty subset (out of four) - as a consequence of the two universal premises of types either (1) or (2) having been taken into account, the resulting ei LC is identical with an LC of a PCP of type (3): one of the 8 subsets of $U$ is definitely not empty. 
There are 8 distinct PCPs of type (3a), E(M*,P*) I(M*,S*), (or Darii/Datisi subtype), and 8 distinct PCPs of type (3b), I(M*,P*) E(M*,S*), (or Disamis/Dimaris subtype). The very short trees "revealing" the LCs are: $\varnothing \neq \mathrm{M} * \mathrm{~S} *=\mathrm{M} * \mathrm{~S} * \mathrm{P} *+\mathrm{M} * \mathrm{~S} * \mathrm{P} * '=\mathrm{M} * \mathrm{~S} * \mathrm{P} * 1$, and, resp., $\varnothing \neq \mathrm{M} * \mathrm{P} *=$ $\mathrm{M} * \mathrm{~S} * \mathrm{P} *+\mathrm{M}^{*} \mathrm{~S}{ }^{* \prime} \mathrm{P} *=\mathrm{M}^{*} \mathrm{~S} * \mathrm{P}^{*}$. Types (1), (2), (3a) and type (3b), together, account for all the 32 PCPs which entail at least one LC. (As noticed, the other 32 PCPs do not entail any LC.) In STM, the eight relabeling transformations, generated by the relabelings $p:=P \leftrightarrow P^{\prime}, s:=S \leftrightarrow S^{\prime}$, $\mathrm{m}:=\mathrm{M} \leftrightarrow \mathrm{M}^{\prime}$ and their compositions, transform VCAs into VCAs of the same (sub)type. As mentioned, this shows that, up to the re-naming/relabeling of which term is called $\mathrm{S}$ and which one is called the $\mathrm{S}^{\prime}$, which term is called $\mathrm{P}$, (resp.M), and which one is called $\mathrm{P}^{\prime}$, (resp. $\mathrm{M}^{\prime}$ ), all of the same (sub)type VCAs are equivalent, which also means that each VCA may be re-formulated as any of the VCAs of the same (sub)type. Moreover, the relabeling $\mathrm{S} \leftrightarrow \mathrm{P}$ obviously maps subtype (3a) VCAs onto the subtype (3b) VCAs and vice versa. If one adheres to the convention that the premise firstly listed contains the $\mathrm{P}$ term, the relabeling $\mathrm{S} \leftrightarrow \mathrm{P}$ amounts, when specific terms are substituted for the letters $\mathrm{S}$ and $\mathrm{P}$, to a switch of the premises' order. (This same argument is used by CCS to disregard the PCPs whose entailed LCs are A(P,S) or $\mathrm{O}(\mathrm{P}, \mathrm{S})$ : modulo a "premise switching" they would generate VS.) The short way to show that each of the three PCP types can be written, respectively as a Barbara, Darapti, and Darii VCAs is as follows. Write the type (1) VCAs, E(M*,P*)E( $\left.M^{* 1}, S^{*}\right): S^{*}=S^{*} M^{*} P^{* \prime}$, $\mathrm{P}^{*}=\mathrm{S}^{* \prime} \mathrm{M}^{* \prime} \mathrm{P}^{*}$, as $\mathrm{A}\left(\mathrm{M}^{*}, \mathrm{P}^{* \prime}\right) \mathrm{A}\left(\mathrm{S}^{*}, \mathrm{M}^{*}\right): \mathrm{A}\left(\mathrm{S}^{*}, \mathrm{P}^{* \prime}\right)=\mathrm{A}\left(\mathrm{P}^{*}, \mathrm{~S}^{* \prime}\right)$, where $\mathrm{S}^{*} \in\left\{\mathrm{S}, \mathrm{S}^{\prime}\right\}, \mathrm{M}^{*} \in\left\{\mathrm{M}, \mathrm{M}^{\prime}\right\}$, $\mathrm{P}^{*} \in\left\{\mathrm{P} \mathrm{P}^{\prime}\right\}$. These are eight Barbara VCAs in the $\mathrm{S}^{*}, \mathrm{M}^{*}, \mathrm{P}^{* 1}$ variables. (The transition from one triplet of $\mathrm{S}^{*}, \mathrm{M}^{*}, \mathrm{P}^{* 1}$ values to another can be interpreted as a term relabeling transformation - for more details see Section 6.) Write the type (2) VCAs, E( $\left.\mathrm{M}^{*}, \mathrm{P}^{*}\right) \mathrm{E}\left(\mathrm{M}^{*}, \mathrm{~S}^{*}\right): \mathrm{M}^{*}=\mathrm{S}^{*} \mathrm{M}^{*} \mathrm{P}^{* \prime}$, as $\mathrm{A}\left(\mathrm{M}^{*}, \mathrm{P}^{* \prime}\right) \mathrm{A}\left(\mathrm{M}^{*}, \mathrm{~S}^{* \prime}\right)$ : I( $\left.\mathrm{S}^{* \prime}, \mathrm{P}^{* \prime}\right)$ if $\mathrm{M}^{*} \neq \varnothing$. These are eight Darapti VCAs in the $\mathrm{M}^{*}, \mathrm{~S}^{* \prime}, \mathrm{P}^{* \prime}$ variables. Write the type (3a) VCAs, E(M*, $\left.\mathrm{P}^{*}\right) \mathrm{I}\left(\mathrm{M}^{*}, \mathrm{~S}^{*}\right)$ : $\mathrm{M}^{*} \mathrm{~S}^{*} \mathrm{P}^{* \prime} \neq \varnothing$, as $\mathrm{A}\left(\mathrm{M}^{*}, \mathrm{P}^{* \prime}\right) \mathrm{I}\left(\mathrm{M}^{*}, \mathrm{~S}^{*}\right)$ : $\mathrm{I}\left(\mathrm{S}^{*}, \mathrm{P}^{* \prime}\right)$. These are eight Darii VCAs in the $\mathrm{M}^{*}, \mathrm{~S}^{*}, \mathrm{P}^{* \prime}$ variables. In the type (3b) VCAs, I(M*, $\left.\mathrm{P}^{*}\right)$ $\mathrm{E}\left(\mathrm{M}^{*}, \mathrm{~S}^{*}\right): \mathrm{M}^{*} \mathrm{P}^{*} \mathrm{~S}^{*} \neq \varnothing$, switch the premises order and apply the convention that the firstly listed premise contains the $\mathrm{P}$ term, or, equivalently, perform the relabeling $\mathrm{S} \leftrightarrow \mathrm{P}$, then switch the premises, to obtain exactly the eight Darii (3a) VCAs.

The rest of the paper expounds on the VCA focused STM, and comments (some more) on the VS focused CCS.

\section{STM and the Karnaugh map for $n=3$ (drawn for subsets instead of truth values)}

\begin{tabular}{|l|l|l|l|}
\hline S'P'M & SP'M & SPM & S'PM \\
\hline S'P'M' $^{\prime}$ & SP'M' & SPM' & S'PM' \\
\hline
\end{tabular}

Fig. 1

The universal set $\mathrm{U}$ is graphed as a rectangle - but the left and right borders of the rectangle are glued together to generate a cylinder, so that S'PM and S'P'M, (resp. S'PM' and S'P'M'), are adjacent. One may easily check that the eight subsets of the Marquand (1881) - Veitch (1952) Karnaugh (1953) map for $n=3$, display/possess the same adjacency as the seven subsets from the 3circle Venn diagram, (Venn, 1880), to which one adds an eighth set, S'P'M' - drawn around the three $\mathrm{S}, \mathrm{P}, \mathrm{M}$ intersecting Venn circles. This means, e.g., that after Barbara's premises empty 4 subsets out of 8 , the other 4 subsets left would be disconnected on a rectangular diagram, but are still connected on the Karnaugh cylindrical map, and still satisfy $\mathrm{S} \subseteq \mathrm{M} \subseteq \mathrm{P}$. Since the 8 subsets of Figure 1 are the "elementary" subsets of U, one calls them just subsets; no other set will be a "subset". On this 
Karnaugh map one can see that any universal premise empties two "horizontal subsets" located either on the $\mathrm{M}$ or the $\mathrm{M}^{\prime}$ row, and its contradictory particular premise places set elements in at least one of the same two "horizontal subsets" emptied by the contradictory universal premise. This makes it clear that a PCP made of two particular premises does not entail any LC (beyond a possible verbatim repetition of premises' content). Also, there is no LC entailed by any PCP made of one universal premise emptying two subsets on $\mathrm{M}$ ', and a particular premise "acting on M", i.e. placing set elements into two subsets of M, (or the other way around). The Karnaugh map makes it clear that in STM, (and thus in CCS, too), any LC is characterized by the fact that it singles out just one of the 8 subsets partitioning $\mathrm{U}$, and only three types of LCs are possible:

(1) One of the sets $\mathrm{S}$ or $\mathrm{S}^{\prime}$ and one of the sets $\mathrm{P}$ or $\mathrm{P}^{\prime}$, have each three empty subsets and one possibly not empty subset (hence each type (1) PCP entails two LCs), (2) One of M or M' has three empty subsets and one possibly not empty subset, (3) One of the subsets of $U$ is definitely not empty. As mentioned, these three types of LCs are entailed by the following three types of PCPs, whose Karnaugh map action is, respectively: (1) PCPs made of two universal premises, that empty a total of four subsets on different rows - M and M'. In this case the intersecting set of the two sets having three empty subsets and one possibly not empty subset is itself empty - and this is the LC retained by the VS Barbara, Celarent/Cesare and Camestres/Camenes. When, e.g., Celarent's premises empty three subsets of $\mathrm{S}$, they also empty three subsets of $\mathrm{P}$ - hence the two LCs entailed by only one PCP, (and, in turn, each LC implies that $\mathrm{S} \cap \mathrm{P}$ is empty), (2) PCPs made of two universal premises, that empty a total of three subsets on the same row - either M or M', (3) PCPs made of one universal plus one particular premises, one emptying, and one placing elements on subsets of the same row. One can notice that, e.g., a (3a) PCP, E(M,P')I(S,M), Darii/Datisi, (obtained when choosing $\mathrm{S}^{*}=\mathrm{S}$, $\mathrm{M}^{*}=\mathrm{M}, \mathrm{P}^{*}=\mathrm{P}^{\prime}$ in (3a)), and a (3b) PCP, I(M,P)E( $\left.\mathrm{S}^{\prime}, \mathrm{M}\right)$, Disamis/Dimaris, (choose $\mathrm{S}^{*}=\mathrm{S}^{\prime}, \mathrm{M}^{*}=\mathrm{M}$, $\mathrm{P}^{*}=\mathrm{P}$ in $(3 \mathrm{~b})$ ), have the same LC: $\mathrm{SMP} \neq \varnothing$. Analogously Bocardo, O(M,P)A(M,S)=I(M,P')E(M,S') and Ferio/Festino/Ferison/Fresison, E(M,P)I(M,S), have the same LC: SMP' $\neq \varnothing$. Note that all the (3a) VCAs become the (3b) VCAs via a relabeling $\mathrm{S} \leftrightarrow \mathrm{P}$, i.e., on specific VCA examples, one just have to switch the premises' order to obtain a (3b) VCA from a type (3a) VCA, and vice versa, and to keep up with the convention of listing firstly the P- premise. By working with 64 distinct PCPs, STM "raises" on an equal footing any of the 8 subsets partitioning U. Because of this, each one of the 8 subsets of U, S*P*M*, appears as the "subject" of an LC exactly eight times: three times as a "possibly non empty subset" LC of types (1) and (2), $\mathrm{S}^{*}=\mathrm{S}^{*} \mathrm{P}^{*} \mathrm{M}^{*}, \mathrm{P}^{*}=\mathrm{S}^{*} \mathrm{P}^{*} \mathrm{M}^{*}$, (these are LCs of the 8 PCPs of type (1), each entailing two LCs per PCP), and $\mathrm{M}^{*}=\mathrm{S}^{*} \mathrm{P}^{*} \mathrm{M}^{*}$, (this is the LC of one of the eight type (2) PCP), and five times as a "definitely non empty subset" LC, (twice as the LC $\mathrm{S}^{*} \mathrm{P}^{*} \mathrm{M}^{*} \neq \varnothing$ of PCPs of types (3a) and (3b), and 3 times as the ei LC generated by the previous three "universal LC" using ei on $\mathrm{S}^{*}, \mathrm{P}^{*}$ and resp. $\mathrm{M}^{*}$. This shows that STM "likes equally" each of the U's eight subsets. By contrast, CCS "likes only three subsets”, SPM, SP'M, and SP'M': any VS LC asserts that either one of the above three subsets is not empty, (if the PCP contains one particular and one universal premises, both acting on the same set - either $\mathrm{M}$ or $\mathrm{M}^{\prime}$ ), or that one of the above three subsets is the only part of either S,P or M which is possibly left non empty by a PCP containing two universal premises. More precisely, SPM appears as LC of Barbara, Barbari, Bramantip, (but there is no "Bramanta"), Darapti, Darii/Datisi, Disamis/Dimaris; SP'M appears as LC of Celarent/Cesare, Celaront/Cesaro, Felapton/Fesapo, Bocardo, Ferio/Festino/Ferison/ Fresison; SP'M' appears as LC of Camestres/Camenes, Camestros/Camenos and Baroco.

\section{VCA distribution conservation and VCA generalized versions of the RofVS}

We'll list the RofVS, (Copi 2009, Hurley 2008, Stebbing 1961Keynes 1887), in the following order, 
from \#1 to \#5: "the middle term has to be distributed in at least one premise", "two negative premises are not allowed", (these two syllogistic rules refer to the PCPs only - the following three rules refer to the entire syllogism, PCP and LC, and can be used, after being "VCA generalized", to "instantaneously predict" the LCs of any non-ei VCAs and ei VCA of type (2)), "any term distributed in the LC must be distributed in the PCP", (i.e., the distribution of the end terms, P and S can not "increase"), "if either premise is negative, the LC must be negative", "from two universal premises, no particular LC may be drawn". (A $6^{\text {th }}$ RofVS, "if one premise is particular, then the LC is particular" was already shown to be true in the Sections 1 and 2.) The 15 VS satisfy all the RofVS, and the 9 ei VS satisfy all RofVS but the $5^{\text {th }}$ one. But any VCA whose LC is one of the O(P,S) or $\mathrm{A}(\mathrm{P}, \mathrm{S})$ statements also satisfies all the RofVS - which means that the RofVS can "instantaneously" find what the LC should be for those VCAs, too: for example, applied to Bramantip's PCP, the RofVS would choose as LC “All P is S", since in Bramantip's PCP, P is distributed, while S is not. Note that the assertion "it is perfectly alright for a term to be distributed in a premise but not in the conclusion", Hurley p. 287, turns out to be incorrect: unless ei on one of the end terms is involved, the distribution of the end terms is the same in the premises and the $\mathrm{LC}$ - see below the proof of RofVS \#3. Thus, applied to the PCP "Some P is M, No S is M" - having one particular and one negative premises - the RofVS point again to a negative, particular LC, which is the correct one: Some $\mathrm{P}$ is not $\mathrm{S}$. Among the $36 \mathrm{PCPs}$ formulable via positive terms, the RofVS \#1 and \#2 reject the PCPs with two negative premises, EE, EO,OE, which generate, respectively, an ei VCA and two VCAs which all have the same, (affirmative, particular), LC - I( $\left.\mathrm{S}^{\prime}, \mathrm{P}^{\prime}\right)$, and the PCP "All P is M, All $\mathrm{S}$ is $\mathrm{M}$ " where $\mathrm{M}$ is undistributed, which generates an ei VCA whose $\mathrm{LC}$ is again $\mathrm{I}\left(\mathrm{S}^{\prime}, \mathrm{P}^{\prime}\right)$. (As mentioned, the rejection of syllogisms with two negative premises brought the ire of Lewis Carroll: Carroll 1986, p.240 or Carroll, 1958, p.173.) Inside the "restricted universe of the VS", the RofVS can be justified by interpreting the S,P,M terms as sets; this means that the 15 non-ei VS necessarily satisfy all the RofVS - see Hurley (285-291), Stebbing (86-92). Vice versa, accepting by hypothesis that a VS, (and ei VS), is defined as above, (PCP formulable with only positive terms, and LC one of the $\mathrm{A}(\mathrm{S}, \mathrm{P}), \mathrm{O}(\mathrm{S}, \mathrm{P}), \mathrm{E}(\mathrm{S}, \mathrm{P})$ or I(S,P) statements), the RofVS are sufficient to show, without using set modeling, that the only PCPs which generate non-ei VS are the ones which generate the 15 VS. See Hurley (285-291), Stebbing (86-92). But this only shows that the VS which satisfy all the RofVS are the non-ei VS. (The VCAs whose LCs are A(P,S) or O(P,S), also satisfy all the RofVS.) Carroll's algebraic method and the Karnaugh map method of determining what LC a PCP entails - if any, are faster than trying to apply the Venn diagram method, and, as well as the Venn diagram, Carroll's algebraic method and the Karnaugh map method, can find any LC of any PCP even if the LC, the $\mathrm{PCP}$, or both, contain some negative terms, $\left(\mathrm{S}^{\prime}, \mathrm{P}^{\prime}, \mathrm{M}^{\prime}\right)$, or if the $\mathrm{P}$, (or $\left.\mathrm{P}^{\prime}\right)$, term turns out to play in the LC the role of subject instead of predicate. As shown below, the RofVS \#3 to \#6 can predict the LC of any non-ei VCA and ei VCA of type (2), even faster.

"A term is said to be distributed when reference is made to all the individuals denoted by it; it is said to be undistributed when they are only referred to partially, i.e., information is given with regard to a portion of the class denoted by the term, but we are left in ignorance with regard to the remainder of the class." (Keynes, 1887). One may agree that an E(M,P) statement refers to both sets in their totality and thus in $\mathrm{E}(\mathrm{M}, \mathrm{P})$ both $\mathrm{M}$ and $\mathrm{P}$ are distributed. Then one can see that the usual definition of distribution can be recovered just by using obversion and negation of statements, and by proclaiming that in any statement the complement of a set has a distribution opposite to the set itself and the negation of a categorical statement changes the distribution of all its terms. According to the latter definition, in $\mathrm{E}(\mathrm{M}, \mathrm{P}), \mathrm{M}^{\prime}$ and $\mathrm{P}^{\prime}$ are undistributed, (indeed $\mathrm{M}^{\prime}$ includes $\mathrm{P}, \mathrm{E}(\mathrm{M}, \mathrm{P})=\mathrm{A}\left(\mathrm{P}, \mathrm{M}^{\prime}\right)=$ $\mathrm{A}\left(\mathrm{M}, \mathrm{P}^{\prime}\right)$, etc.), and in $\mathrm{I}(\mathrm{M}, \mathrm{P})$, both $\mathrm{M}$ and $\mathrm{P}$ are undistributed, (since they were distributed in the contradictory E statement), and thus $\mathrm{M}^{\prime}$ and $\mathrm{P}^{\prime}$ are distributed; in an $\mathrm{A}(\mathrm{M}, \mathrm{P})=\mathrm{E}\left(\mathrm{M}, \mathrm{P}^{\prime}\right)$ statement, $\mathrm{M}$ 
and $\mathrm{P}^{\prime}$ are distributed while $\mathrm{P}$ and $\mathrm{M}^{\prime}$ are not, and in its contradictory $\mathrm{O}(\mathrm{M}, \mathrm{P})$ statement, $\mathrm{M}$ and $\mathrm{P}^{\prime}$ are thus undistributed, while $\mathrm{P}$ and $\mathrm{M}^{\prime}$ are distributed.

One may now see, from the very way in which the LCs are obtained for each of the three types of non-ei VCAs, that "distribution of the end terms is conserved", i.e., the $\mathrm{S}^{*}$ and $\mathrm{P} *$ terms have the same distribution in the premises and in the LCs of all the three VCA types:

(1) The LC, $\mathrm{S}^{*}=\mathrm{S}^{*} \mathrm{M}^{*} \mathrm{P}^{*}$, ( (see Section 2), can be expressed as All $\mathrm{S}^{*}$ is $\mathrm{P}^{*}$. Thus, in the LC, $\mathrm{S}^{*}$ is distributed and $\mathrm{P}^{* 1}$ is not - the same term distributions as in the $\mathrm{E}\left(\mathrm{M}^{*}, \mathrm{P}^{*}\right) \mathrm{E}\left(\mathrm{M}^{*}, \mathrm{~S}^{*}\right) \mathrm{PCP}$ of type (1), where both $\mathrm{S}^{*}$ and $\mathrm{P}^{*}$ were distributed. The second LC of the same PCP, $\mathrm{P}^{*}=\mathrm{S}^{*} \mathrm{M}^{*} \mathrm{P}^{*}$ can be expressed as All $\mathrm{P}^{*}$ is $\mathrm{S}^{* 1}$, and thus the distribution is again conserved. Imposing the ei conditions, which assure the validity of immediate sub-alternation inferences, one gets the ei LCs $\mathrm{I}\left(\mathrm{S}^{*}, \mathrm{P}^{* \prime}\right)$, (and resp. I $\left(\mathrm{P}^{*}, \mathrm{~S}^{* \prime}\right)$ ), which, as expected, do not conserve anymore the distributions that $\mathrm{S}^{*}$, (and resp. $\mathrm{P}^{*}$ ) had in the PCP or the non-ei LCs, before the ei on $\mathrm{S}^{*}$, (resp. $\mathrm{P}^{*}$ ), was imposed, but the undistribution of the other term, $\mathrm{P}^{* \prime}$, (and resp. $\mathrm{S}^{* \prime}$ ), is still conserved in the ei LC.

(2) The $L C, M^{*}=S^{*} M^{*} P^{* 1}$, or, All $M^{*}$ is $S^{* \prime} M^{*} P^{*}$, which conserves the distributions that $M^{*}, S^{*}$ and $\mathrm{P}^{*}$ had in the PCP, leads, after ei on $\mathrm{M}^{*}$, to the ei $L C I\left(\mathrm{~S}^{*}, \mathrm{P}^{* \prime}\right)$ - the distributions of $\mathrm{S}^{*}$ and $\mathrm{P}^{*}$ are again the same as they were in the $E\left(M^{*}, P^{*}\right) E\left(M^{*}, S^{*}\right) P C P$. Thus, even the distribution of $M^{*}$ is conserved in type (2) VCAs. (While in type (1) and (3) VCAs the distribution of the $M^{*}$ term in the two premises differs!) Moreover, the distribution of the end terms is the same in any PCP of type (2), as it is in its ei LC resulting after the ei on $\mathrm{M}^{*}$, and the $\mathrm{M}^{*}$ elimination from the non-ei $\mathrm{LC}$.

(3a) and (3b) Their respective LCs can be written $\mathrm{I}\left(\mathrm{S}^{*}, \mathrm{P}^{* \prime}\right)$ and $\mathrm{I}\left(\mathrm{P}^{*}, \mathrm{~S}^{* \prime}\right)$. One sees that in the $\mathrm{I}\left(\mathrm{S}^{*}, \mathrm{M}^{*}\right) \mathrm{E}\left(\mathrm{M}^{*}, \mathrm{P}^{*}\right)$ and $\mathrm{I}\left(\mathrm{P}^{*}, \mathrm{M}^{*}\right) \mathrm{E}\left(\mathrm{M}^{*}, \mathrm{~S}^{*}\right) \mathrm{PCPs}$, and in their LCs, the $\mathrm{S}^{*}$ and $\mathrm{P}^{*}$ terms have the same distributions, i.e., the distribution is conserved.

In short, the above proves that: the ei on $\mathrm{M}^{*}$ - in a type (2) VCA - preserves the distributions of both end terms, $\mathrm{S}^{*}$ and $\mathrm{P}^{*}$; the ei on $\mathrm{S}^{*}$, (resp. $\left.\mathrm{P}^{*}\right)$ - in a type (1) VCA - preserves the distribution of $\mathrm{P}^{*}$, (resp. $\mathrm{S}^{*}$ ), and changes the distribution of $\mathrm{S}^{*}$, (resp. $\mathrm{P}^{*}$ ), from distributed to undistributed.

Moreover, in any non-ei VCA, the distribution of the end terms, $\mathrm{S}^{*}$ and $\mathrm{P}^{*}$, is the same in the PCP and the LC; in type (2) VCAs, the distribution of $\mathrm{M}^{*}$ is also the same in the PCP and the LC. This adds more precision to the RofVS "Any term distributed in the conclusion must be distributed in the premises", by pointing out the only cases of ei - on $\mathrm{S}^{*}$ or $\mathrm{P}^{*}$ - when just one "end term", $\mathrm{S}^{*}$ or $\mathrm{P}^{*}$, is distributed in the premises without being distributed in the conclusion. It also turns this RofVS, into an if and only if theorem applicable to any VCA, with the exception of the ei VCA obtained via ei on $\mathrm{S}^{*}$ or $\mathrm{P}^{*}$.

Note that, except for the four PCPs of type (2) acting only on $\mathrm{M}^{\prime}, \mathrm{E}\left(\mathrm{M}^{\prime}, \mathrm{P}^{*}\right) \mathrm{E}\left(\mathrm{M}^{\prime}, \mathrm{S}^{*}\right)$, in any of the three types of PCPs, the middle term M is distributed at least once. (For example, if the PCPs (3a) and ( $3 \mathrm{~b}$ ) act on/contain $\mathrm{M}$, then $\mathrm{M}$ is distributed in the the universal premise, if they act on/contain $\mathrm{M}^{\prime}$, then $\mathrm{M}$ is distributed in the the particular premise.) In the case of the $\mathrm{E}\left(\mathrm{M}^{\prime}, \mathrm{P}^{*}\right) \mathrm{E}\left(\mathrm{M}^{\prime}, \mathrm{S}^{*}\right) \mathrm{PCPs}$, one may argue that the real middle term is $\mathrm{M}^{\prime}$ not $\mathrm{M}$, or, in classical fashion, one may discard, as a VS candidate, a PCP similar to "All dogs are animals", "All cats are animals", as not entailing an LC, (meaning, in fact, an LC formulable with positive terms only), because the middle term does not satisfy the RofVS "The middle term has to be distributed in at least one premise". As mentioned above, the LC of the above PCP with undistributed middle is actually $\mathrm{M}^{\prime}=\mathrm{M}^{\prime} \mathrm{S}^{*} \mathrm{P} \mathrm{P}^{* 1}$, where $\mathrm{M}=$ animals, $\mathrm{P}^{*}=\operatorname{dogs}, \mathrm{S}^{*}=$ cats, which translates to "All non-animals are non-dogs and non-cats". Using ei on M' (the non-animals), one finds out that "Some non-cats are non-dogs", take, e.g., mosquitoes. Thus the rule that the middle term $\mathrm{M}$ has to be distributed in at least one premise eliminates, out of the 36 PCPs containing just positive terms, the only one PCP of type (2) acting on M': A(P,M)A(S,M). Copying Carroll's "example strategy" of making the negative terms as intuitive as the positive ones, consider this PCP: All the desire of fighting is in my boys. All the desire of 
playing sports is in my boys. The middle term, my boys, is undistributed, but if the universe of discourse is my children and their desires, then the complementary set of my boys is my girls. So, through obversions, the above PCP becomes one made of two negative premises: No desire of fighting is in my girls. No desire of playing sports is in my girls. Which, as well as the initial PCP, has this LC: My girls have no desire or fighting, nor of playing sports. If the set of my girls is nonempty, the ei LC is that there are Some girls who have no desire or fighting, nor of playing sports. According to the definitions below, this is an affirmative particular proposition: I( $\left.\mathrm{S}^{\prime}, \mathrm{P}^{\prime}\right)$, with $\mathrm{S}^{\prime}, \mathrm{P}^{\prime}$ undistributed, (and therefore S,P distributed), in the LC, and S,P also distributed in the PCP, i.e., for type (2) PCPs, the distribution of the end terms is conserved even after ei on M is imposed. Note also that Baroco, All P is M, Some S is not M, (or E'I'), is of type (3a), and acts on $\mathrm{M}^{\prime}$ - with M undistributed in the universal premise and $M$ distributed in the particular premise. But I'E':O(P,S), which also satisfies all five RofVS, is nevertheless disregarded by CCS due to the "wrong" O(P,S) LC. In general, if an $\alpha \beta$ PCP has an A(S,P), (or O(S,P)), LC, then the LC of the $\beta \alpha$ PCP will be $\mathrm{A}(\mathrm{P}, \mathrm{S})$, (resp. $\mathrm{O}(\mathrm{P}, \mathrm{S}))$. From the Euler graphs of the VCAs it results that either $\mathrm{M}$, or M', or both, are distributed in at least one premise in any of the 64 PCPs containing both positive and negative terms: in type (1) PCPs because $M^{*}$ appears in the middle of a double inclusion; in type (2) PCPs because $M^{*}$ is included in both $\mathrm{S}^{* 1}$ and $\mathrm{P}^{*}$; in type (3) PCPs because $\mathrm{M}^{*}$, in accordance with the universal premise, can be seen as included in either $\mathrm{S}^{* \prime}$ or $\mathrm{P}^{* \prime}$. In type (2) PCPs, $\mathrm{M}$ is undistributed only in 4 PCPs: E(M',P*) $\mathrm{E}\left(\mathrm{M}^{\prime}, \mathrm{S}^{*}\right)$. With respect to the $3^{\text {rd }}$ RofVS, "a term can not be distributed in the LC unless is distributed in the corresponding premise", one has seen that the distribution of the $\mathrm{S}^{*}$ and $\mathrm{P}^{*}$ terms is conserved in all non-ei VCAs, and that even the distribution of all the terms is conserved in type (2) ei and non-ei VCAs, $\mathrm{E}\left(\mathrm{M}^{*}, \mathrm{P}^{*}\right) \mathrm{E}\left(\mathrm{M}^{*}, \mathrm{~S}^{*}\right): \mathrm{M}^{*}=\mathrm{M}^{*} \mathrm{~S}^{*} \mathrm{P}^{*}$. The $5^{\text {th }}$ and $6^{\text {th }}$ RofVS were shown to be true in Section 1 . To prove the $4^{\text {th }}$ RofVS, ("if either premise is negative, the LC must be negative"), for any VCA one needs to firstly define, for both universal and particular premises, when they are considered as affirmative and when they are considered as negative statements. The universal negative premises are $\mathrm{E}(\mathrm{M}, \mathrm{P}), \mathrm{E}(\mathrm{M}, \mathrm{S}), \mathrm{E}\left(\mathrm{M}^{\prime}, \mathrm{P}^{\prime}\right)$, $\mathrm{E}\left(\mathrm{M}^{\prime}, \mathrm{S}^{\prime}\right)$, and the only particular negative premises are $\mathrm{O}(\mathrm{P}, \mathrm{M}), \mathrm{O}(\mathrm{S}, \mathrm{M}), \mathrm{O}(\mathrm{M}, \mathrm{P})$, and $\mathrm{O}(\mathrm{M}, \mathrm{S})$. Denoting $\mathrm{h} \in\{\mathrm{S}, \mathrm{P}\}$, the universal negative premises are $\mathrm{E}(\mathrm{M}, \mathrm{h}), \mathrm{E}\left(\mathrm{M}^{\prime}, \mathrm{h}^{\prime}\right)$, the particular negative premises are $\mathrm{I}\left(\mathrm{M}^{\prime}, \mathrm{h}\right), \mathrm{I}\left(\mathrm{M}, \mathrm{h}^{\prime}\right)$, the universal affirmative premises are $\mathrm{E}\left(\mathrm{M}^{\prime}, \mathrm{h}\right)=\mathrm{A}(\mathrm{h}, \mathrm{M}), \mathrm{E}\left(\mathrm{M}, \mathrm{h}^{\prime}\right)=\mathrm{A}(\mathrm{M}, \mathrm{h})$, the particular affirmative premises are I(M,h), I(M',h'). One can see that the switch $\mathrm{E} \leftrightarrow \mathrm{I}$ while the arguments are left unchanged transforms universal negative premises into particular affirmative premises and vice versa, and transforms universal affirmative premises into particular negative premises and vice versa. The switch $\mathrm{M} \leftrightarrow \mathrm{M}^{\prime}$ transforms affirmative premises into negative premises and vice versa. Based on these observations one can verify a generalized RofVS \#4: Two affirmative premises, (as in Barbara or Darii), entail an affirmative LC; two negative premises, (as in Barbara' or Darii', i.e., same premises as Barbara and Darii except for the substitution or switch $M \leftrightarrow M^{\prime}$ ), entail an affirmative LC; one affirmative plus one negative premises entail a negative LC - as in Celarent/Cesare, (aka Camestres'/Camenes'), and Camestres/Camenes, (aka Celarent'/Cesare'). The proof by the 32 cases of PCPs which entail at least an LC, may be organized according to how many negative terms, $(0,1$ or 2$)$, the $\left(\mathrm{S}^{*}, \mathrm{P}^{*}\right)$ pair has - this determines how many affirmative or negative premises a PCP has, and determines if, after the $\mathrm{M}^{*}$ elimination, the LC is affirmative or negative. No matter what PCP type one considers, it results that two affirmative or two negative premises entail an affirmative LC, and one negative plus one affirmative premises entails a negative LC. Example of the latter case: $\mathrm{E}(\mathrm{M}, \mathrm{P}) \mathrm{E}\left(\mathrm{S}, \mathrm{M}^{\prime}\right)$ : $\mathrm{S}=\mathrm{SMP}$ ' or $\mathrm{E}(\mathrm{S}, \mathrm{P})$, and, $\mathrm{P}=\mathrm{PM}$ 'S' or $\mathrm{E}(\mathrm{S}, \mathrm{P})-$ Celarent/Cesare's PCP entails two LCs, both negative (and universal). But two negative premises, $E(M, P) E(M, S)$ entail a positive ei $L C$ : $M=M P^{\prime} S^{\prime}, M \neq \varnothing$, so $I\left(S^{\prime}, P^{\prime}\right)$. (One sees, once more, that the positive and negative terms appear "on equal footing". One can use the list of 64 PCPs appearing in Section 6 to check the above generalization of RofVS \#4.) 
When three specific terms are given, writing down all 36 or 64 PCPs means trying to see what sound VS or VCAs may one get out of the three terms. As an example take the IE PCP. It has conceivable true premises when $\mathrm{M}=$ barking creatures, $\mathrm{P}=\operatorname{dogs}, \mathrm{S}=$ cats. Then its $\mathrm{LC}, \mathrm{MPS} \neq \varnothing$, or $\mathrm{O}(\mathrm{P}, \mathrm{S})$, is also true: Some dogs are not cats. But any EI, i.e., Ferio type VS with the same terms has false premises: No barking creatures are dogs, Some cats are barking creatures, even if its O(S,P) LC is still true: Some cats are not dogs. But if one just switches the order of the IE premises, one gets an EI Ferio type VS with true premises, and a true $\mathrm{O}(\mathrm{S}, \mathrm{P}) \mathrm{LC}$. In this case, re-purposing, via switching the premises' order, the IE PCP, as a Ferio's EI PCP, could not produce confusion since at most one PCP out of the two may have true premises. Contradictory or contrary relationships hold as well between the other four PCPs having $\mathrm{A}(\mathrm{P}, \mathrm{S})$ or $\mathrm{O}(\mathrm{P}, \mathrm{S})$ as LCs, and their corresponding VS with $\mathrm{A}(\mathrm{S}, \mathrm{P})$ or $\mathrm{O}(\mathrm{S}, \mathrm{P}) \mathrm{LCs}$ : $\mathrm{E}^{\prime} \mathrm{A}=\mathrm{A}(\mathrm{P}, \mathrm{M}) \mathrm{A}(\mathrm{M}, \mathrm{S})$, implies $\mathrm{P} \subseteq \mathrm{M} \subseteq \mathrm{S}$, and $\mathrm{AE}^{\prime}$ (Barbara), implies $\mathrm{S} \subseteq \mathrm{M} \subseteq \mathrm{P}$, i.e., unless $\mathrm{P} \equiv \mathrm{S} \equiv \mathrm{M}$, the PCPs contradict each other "pairwise". $\mathrm{AE}=\mathrm{A}(\mathrm{M}, \mathrm{P}) \mathrm{E}(\mathrm{M}, \mathrm{S})$ and $\mathrm{EA}=\mathrm{E}(\mathrm{M}, \mathrm{P}) \mathrm{A}(\mathrm{M}, \mathrm{S})$ (Felapton/Fesapo) have premises contraries to one another. Thus, unless $\mathrm{P}$, or S, or both, are empty sets, if AE premises are true, those of Felapton/Fesapo are false and vice versa. AO and OA (Bocardo) have contradictory premises, and I'E' and E'I' (Baroco) also have contradictory premises. But note that IE, E'A, AE, AO, I'E' and their LCs, satisfy all five RofVS.

Not admitting negative terms in the LC is what justifies discarding the $\mathrm{I}\left(\mathrm{S}^{\prime}, \mathrm{P}^{\prime}\right) \mathrm{LC}$ and the corresponding PCPs that entail it: EE, E'E', OE, EO. Using the above shorthand notation and the convention of listing the P-premise first, EE means $\mathrm{E}(\mathrm{M}, \mathrm{P}) \mathrm{E}(\mathrm{M}, \mathrm{S})$ and $\mathrm{E}^{\prime} \mathrm{E}^{\prime}$ means $\mathrm{A}(\mathrm{P}, \mathrm{M}) \mathrm{A}(\mathrm{S}, \mathrm{M})$, etc. In CCS one may use the RofVS "two negative premises are not allowed" and "the middle term has to be distributed in at least one premise" to justify removing these four PCPs from the list of VS candidates. In STM one may disregard these first two RofVS since they "eliminate" perfectly valid VCAs, and one may say that all VCAs satisfy the RofVS \#3 to \#6, which fulfill the role of rapidly predicting the LC of any VCA. In particular, all the VCAs whose LCs are A(P,S) or O(P,S), satisfy all the RofVS, while in general, a VCA satisfies only the generalized RofVS \#3 and \#4, and the usual RofVS \#5 and \#6.

As noted above, if the LC is an E or I statement, CCS recognizes, by accepting the validity of the conversions, $\mathrm{E}(\mathrm{S}, \mathrm{P})=\mathrm{E}(\mathrm{P}, \mathrm{S})$ and $\mathrm{I}(\mathrm{S}, \mathrm{P})=\mathrm{I}(\mathrm{P}, \mathrm{S})$, that it can not pinpoint/define anymore which one is the ("true") predicate. This explains why Bramantip is an accepted ei VS, but "Bramanta" has to be repurposed as Barbara.

If one compares $\mathrm{E}^{\prime} \mathrm{E}$ (the premises of Camestres/Camenes) with $\mathrm{EE}^{\prime}$ (the premises of Celarent/ Cesare) one sees that the two pairs of premises are contraries to each other - even if both are recognized as distinct VS, and no repurposing/switching around of the premises is required. The same direct reduction transforms one VS into the other one, via a switch of premises' order and/or a relabeling/re-lettering $\mathrm{P} \leftrightarrow \mathrm{S}$. If one works in abstracto, with term variables, the re-lettering has to be explicitly performed; if one works with specific terms, the re-lettering is implicitly performed as soon as the premises' order is switched - the old subject becomes predicate and vice versa - in accordance with the convention that the premise listed firstly contains the $\mathrm{P}$ term. Thus starting with a concrete example of a Camestres/ Camenes PCP, All barking animals are dogs, No cats are dogs, the LC is No barking animals are cats. But just by firstly uttering No cats are dogs, and, then, All barking animals are dogs, and following the convention that the premise listed firstly contains the $\mathrm{P}$ term, one gets Celarent/Cesare's PCP, having the same LC, and, in the CCS view, what was done above is a direct reduction of Camestres/Camenes to Celarent/Cesare, and no PCP repurposing is implied or necessary. Note also that instead of switching the premises' order and performing an implicit re-lettering $\mathrm{S} \leftrightarrow \mathrm{P}$ in accordance with the convention that the premise listed first contains the $\mathrm{P}$ term, one may perform the transformation of Camestres/Camenes to Celarent/Cesare and vice versa via a re-lettering $\mathrm{M} \leftrightarrow \mathrm{M}^{\prime}$, or, equivalently, one may leave the Camestres/Camenes premises' order unchanged, but re-express them using $\mathrm{M}^{\prime}=$ non-dogs instead of $\mathrm{M}=$ dogs: thus All barking 
animals are dogs becomes All barking animals are not non-dogs= No barking animals are non-dogs, and No cats are dogs becomes No cats are not non dogs=All cats are non-dogs. One thus again obtains, from a Camestres/Camenes PCP, a Celarent/Cesare PCP where the middle term is now nondogs, but still the "content" and LC of the "new" Celarent/Cesare are the same as the content and LC of the Celarent/Cesare obtained via classical/Aristotelian direct reduction of the initial Camestres/ Camenes. In general, without changing its content or its LC, any VCA may be re-written as any other VCA of the same type. Since there are three different types of VCA, (and VS), any VCA may be written as either a Barbara/Barbari, a Darapti, or a Darii VS- see below. By contrast, the Celarent/Cesare PCP with the same $\mathrm{M}=\operatorname{dogs}, \mathrm{P}=$ barking animals and $\mathrm{S}=$ cats, has false premises: No barking animals are dogs, All cats are dogs, (even if its LC is still true: No barking animals are cats). Since the LC is the symmetric E(S,P), the premises of Celarent/Cesare, E(M,P)A(S,M), and of Camestres/ Camenes, $\mathrm{A}(\mathrm{P}, \mathrm{M}) \mathrm{E}(\mathrm{M}, \mathrm{S})$ are both accepted by CCS as generating distinct VS even if their premises are contraries. As are accepted as generating ei VS, the incompatible premises of both Barbari and Bramantip, whose LCs are the same, I(S,P) - after ei on S and resp. P. But "Bramanta"s PCP - which is the same as Bramantip's PCP - is repurposed as Barbara's PCP, with no implied confusion, since if its premises are true, Barbara's premises, built with the same $\mathrm{P}$ and $\mathrm{S}$ as Bramanta's before the switch $\mathrm{S} \leftrightarrow \mathrm{P}$, are false. In STM, P and S are just term names; by convention, the term which appears in both premises is denoted by $\mathrm{M}$, the other term in whatever premise is listed firstly is denoted by $\mathrm{P}$, and the third term is denoted by $\mathrm{S} ; \mathrm{A}(\mathrm{P}, \mathrm{S})$ and $\mathrm{O}(\mathrm{P}, \mathrm{S})$ are accepted LCs, and no PCP is repurposed via its premises' order being switched around. Instead, STM discards redundant syllogistic figure information: Ferio/Festino/Ferison/Fresison are "lumped together" as a VS whose PCP is E(M,P)I(M,S) and LC is $\mathrm{O}(\mathrm{S}, \mathrm{P})$. But STM has "nothing against" a VCA whose PCP is, e.g., I(M,P)E(M,S) and whose LC is thus O(P,S). The VS Barbara may be written as a Celarent/Cesare VS, or vice versa, via a $\mathrm{P} \leftrightarrow \mathrm{P}^{\prime}$ relabeling, and the whole set of $8 \mathrm{VCA}$ of the same type as Barbara, Celarent/Cesare, Camestres/Camenes, "Bramanta", etc., transform into one another via the relabelings $\mathrm{p}:=\mathrm{P} \leftrightarrow \mathrm{P}^{\prime}, \mathrm{s}:=\mathrm{S} \leftrightarrow \mathrm{S}^{\prime}, \mathrm{m}:=\mathrm{M} \leftrightarrow \mathrm{M}^{\prime}$ and their compositions - see Section 1 above. Since STM is a model for CCS, all VCAs are clearly valid inferences - one does not have to perform any validity proof. Instead of the CCS' $1^{\text {st }}$ Figure reduction validity proofs initiated by Aristotle himself, one may concentrate instead on "clusters" of compatible PCPs. The conclusion is, that after much discussions about VS or VCAs, when any three concrete/specific terms are given, there are not many sound VCAs one may construct out of them, no matter by what names one denotes them: S,P,M or, maybe, S',P',M'.

\section{Sorites}

Using the same notations as those from Section 1, the three types of PCPs which generate VCAs may be immediately extended to sorites of the same type:

Type (1). The premises of the "Barbara type" Aristotelian/Goclenian sorite:

$$
\begin{aligned}
& \text { SOR1:=E( }\left(\mathrm{S}^{*}, \mathrm{M}_{1}{ }^{*}\right) \mathrm{E}\left(\mathrm{M}_{1}{ }^{* \prime}, \mathrm{M}_{2}{ }^{*}\right) \mathrm{E}\left(\mathrm{M}_{2}{ }^{* \prime}, \mathrm{M}_{3}{ }^{*}\right) \ldots \mathrm{E}\left(\mathrm{M}_{\mathrm{n}}{ }^{* \prime}, \mathrm{P}^{*}\right)=\mathrm{A}\left(\mathrm{S}^{*}, \mathrm{M}_{1}{ }^{* \prime}\right) \mathrm{A}\left(\mathrm{M}_{1}{ }^{* \prime}, \mathrm{M}_{2}{ }^{* \prime}\right) \mathrm{A}\left(\mathrm{M}_{2}{ }^{* \prime},\right. \\
& \left.\mathrm{M}_{3}^{* \prime}\right) \ldots \mathrm{A}\left(\mathrm{M}_{\mathrm{n}}^{* \prime}, \mathrm{P}^{* \prime}\right) \\
& \mathrm{LC}_{1}: \mathrm{S}^{*}=\mathrm{S}^{*} \mathrm{M}_{1}{ }^{* \prime} \mathrm{M}_{2}{ }^{* \prime} \mathrm{M}_{3}{ }^{* \prime} \ldots \mathrm{M}_{\mathrm{n}}{ }^{*} \mathrm{P} \mathrm{P}^{* \prime} \text {. (the Aristotelian logical consequence) } \\
& \mathrm{LC}_{2}^{1}: \mathrm{P} *=\mathrm{P} * \mathrm{M}_{\mathrm{n}} * \ldots \mathrm{M}_{3} * \mathrm{M}_{2} * \mathrm{M}_{1} * \mathrm{~S} * 1=\mathrm{P} * \mathrm{M}_{1} * \mathrm{M}_{2} * \mathrm{M}_{3} * \ldots \mathrm{M}_{\mathrm{n}} * \mathrm{~S} *{ }^{\prime} \text { (the Goclenian logical consequence }
\end{aligned}
$$

of the same premises. As in Barbara's case, the two LCs are not independent because they are based 
on two chain of inclusions which are deducible one from the other: $\mathrm{P} * \subseteq \mathrm{M}_{\mathrm{n}}{ }^{*} \subseteq . . \subseteq \mathrm{M}_{3}{ }^{*} \subseteq \mathrm{M}_{2} *$ $\subseteq \mathrm{M}_{1}{ }^{*} \subseteq \mathrm{S}^{* \prime}$ and $\left.\mathrm{S} \mathrm{S}^{*} \mathrm{M}_{1}{ }^{*} \subseteq \mathrm{M}_{2}{ }^{*} \subseteq \mathrm{M}_{3}{ }^{*} \subseteq . . \subseteq \mathrm{M}_{\mathrm{n}}{ }^{*} \subseteq \mathrm{P}^{* \prime}.\right)$

Type (2). The premises of the "Darapti type" sorite are:

SOR2:=E( $\left.S^{*}, M^{*}\right) E\left(M_{1}^{*}, M^{*}\right) E\left(M_{2}^{*}, M^{*}\right) \ldots E\left(M_{i}^{*}, M^{*}\right) E\left(M_{i+1}{ }^{*}, M^{*}\right) \ldots E\left(M_{n}^{*}, M^{*}\right) E\left(M^{*}, P^{*}\right)$ LC: $M^{*}=M^{*} S^{* \prime} M_{1}{ }^{* \prime} M_{2}{ }^{* \prime} M_{3}{ }^{* \prime} \ldots M_{i}^{* \prime} M_{i+1}{ }^{* \prime} \ldots M_{n}{ }^{* \prime} P^{* \prime}$ with, if $M^{*} \neq \varnothing$, some of the many ei LCs being $\mathrm{S}^{* \prime} \mathrm{M}_{1}{ }^{* \prime} \mathrm{M}_{2}{ }^{* \prime} \mathrm{M}_{3}{ }^{* \prime} \ldots \mathrm{M}_{\mathrm{i}}^{* \prime} \mathrm{M}_{\mathrm{i}+1}{ }^{* \prime} \ldots \mathrm{M}_{\mathrm{n}}{ }^{* \prime} \mathrm{P}{ }^{* \prime} \neq \varnothing, \mathrm{I}\left(\mathrm{S}^{* \prime}, \mathrm{P}^{* \prime}\right)$, etc.

Type (3). The premises of the "Darii type" sorite are:

$$
\begin{gathered}
\text { SOR3:=E( } \left.S^{*}, M_{x}^{*}\right) E\left(M_{1}{ }^{*}, M_{y}^{*}\right) E\left(M_{2}{ }^{*}, M_{y}^{*}\right) \ldots I\left(M_{x}^{*}, M_{y}^{*}\right) \ldots E\left(M_{i}^{*}, M_{y}^{*}\right) E\left(M_{i+1} *\right. \\
\left.M_{x}^{*}\right) \ldots E\left(M_{n}^{*}, M_{y}^{*}\right) E\left(M_{x}^{*}, P^{*}\right)
\end{gathered}
$$

$\mathrm{LC}: \mathrm{M}_{\mathrm{x}}{ }^{*} \mathrm{M}_{\mathrm{y}}{ }^{*} \mathrm{~S}^{* \prime} \mathrm{M}_{1}{ }^{* \prime} \mathrm{M}_{2}{ }^{* \prime} \mathrm{M}_{3}{ }^{* \prime} \ldots \mathrm{M}_{\mathrm{i}}^{* \prime} \mathrm{M}_{\mathrm{i}+1}{ }^{* \prime} \ldots \mathrm{M}_{\mathrm{n}}^{* \prime} \mathrm{P} * \prime \neq \varnothing$

Note that there is just one particular premise and the rest are universal premises, all "related" to the particular premise.

Also note that each of the three type sorites admits "Darapti decorations", i.e., a Darapti type sequence of premises may be added using any term/letter as the "base" - exactly as the term (or letter) M was used as the "base" of SOR2 - the Darapti type (2) sorite above.

For example, if to SOR1 one adds Darapti decorations of length=1 on $\mathrm{S}^{*}, \mathrm{M}_{1}{ }^{* 1}$, and $\mathrm{P}^{* \prime}$, respectively, and a Darapti decoration of length $=3$ on $\mathrm{M}_{2}{ }^{* 1}$, i.e., if one adds these premises: $\mathrm{E}\left(\mathrm{S}^{*}\right.$, $\left.\mathrm{M}_{\mathrm{n}+1}{ }^{*}\right) \mathrm{E}\left(\mathrm{M}_{1}{ }^{* 1}, \mathrm{M}_{\mathrm{n}+2}{ }^{*}\right) \mathrm{E}\left(\mathrm{M}_{2}{ }^{* \prime}, \mathrm{M}_{\mathrm{n}+3}{ }^{*}\right) \mathrm{E}\left(\mathrm{M}_{2}{ }^{* 1}, \mathrm{M}_{\mathrm{n}+4}{ }^{*}\right) \mathrm{E}\left(\mathrm{M}_{2}{ }^{* 1}, \mathrm{M}_{\mathrm{n}+5}{ }^{*}\right) \mathrm{E}\left(\mathrm{P}^{* 1}, \mathrm{M}_{\mathrm{n}+6}{ }^{*}\right)$, then one obtains a sorite which has just one LC not two. This LC is an "extension" of $\mathrm{LC}_{1}$ :

$\mathrm{S}^{*}=\mathrm{S}^{*} \mathrm{M}_{1}{ }^{* \prime} \mathrm{M}_{2}{ }^{* \prime} \mathrm{M}_{3}{ }^{* \prime} \ldots \mathrm{M}_{\mathrm{n}}^{*} \mathrm{P}{ }^{* \prime} \mathrm{M}_{\mathrm{n}+1}{ }^{* \prime} \mathrm{M}_{\mathrm{n}+2}{ }^{* \prime} \mathrm{M}_{\mathrm{n}+3}{ }^{* \prime} \mathrm{M}_{\mathrm{n}+4}{ }^{* \prime} \mathrm{M}_{\mathrm{n}+5}{ }^{* \prime} \mathrm{M}_{\mathrm{n}+6}{ }^{* \prime}$.

For the Goclenian reading of SOR1 one needs to add, as Darapti decorations of the same lengths as above, e.g., these premises:

$\mathrm{E}\left(\mathrm{S}^{* \prime}, \mathrm{M}_{\mathrm{n}+1}{ }^{*}\right) \mathrm{E}\left(\mathrm{M}_{1} *, \mathrm{M}_{\mathrm{n}+2}{ }^{*}\right) \mathrm{E}\left(\mathrm{M}_{2}{ }^{*}, \mathrm{M}_{\mathrm{n}+3}{ }^{*}\right) \mathrm{E}\left(\mathrm{M}_{2}{ }^{*}, \mathrm{M}_{\mathrm{n}+4}{ }^{*}\right) \mathrm{E}\left(\mathrm{M}_{2}{ }^{*}, \mathrm{M}_{\mathrm{n}+5}{ }^{*}\right) \mathrm{E}\left(\mathrm{P} *, \mathrm{M}_{\mathrm{n}+6}{ }^{*}\right)$, and then, again, one obtains a sorite which has just one LC not two. This LC is an "extension" of $\mathrm{LC}_{2}$ : $\mathrm{P} *=\mathrm{P} * \mathrm{M}_{1} * \mathrm{M}_{2} * \mathrm{M}_{3} * \ldots \mathrm{M}_{\mathrm{n}} * \mathrm{~S} * \mathrm{M}_{\mathrm{n}+1}{ }^{* \prime} \mathrm{M}_{\mathrm{n}+2}{ }^{* \prime} \mathrm{M}_{\mathrm{n}+3}{ }^{* \prime} \mathrm{M}_{\mathrm{n}+4} * \mathrm{M}_{\mathrm{n}+5}{ }^{* \prime} \mathrm{M}_{\mathrm{n}+6}{ }^{* \prime}$.

One may add Darapti decorations to a Darapti type sorite, SOR2, via adding, e.g., these premises: $\mathrm{E}\left(\mathrm{S}^{* \prime}, \mathrm{M}_{\mathrm{n}+1}{ }^{*}\right) \mathrm{E}\left(\mathrm{M}_{1}{ }^{* 1}, \mathrm{M}_{\mathrm{n}+2}{ }^{*}\right) \mathrm{E}\left(\mathrm{M}_{2}{ }^{* \prime}, \mathrm{M}_{\mathrm{n}+3}{ }^{*}\right) \mathrm{E}\left(\mathrm{M}_{2}{ }^{* 1}, \mathrm{M}_{\mathrm{n}+4}{ }^{*}\right) \mathrm{E}\left(\mathrm{M}_{2}{ }^{* 1}, \mathrm{M}_{\mathrm{n}+5}{ }^{*}\right) \mathrm{E}\left(\mathrm{P}^{* 1}, \mathrm{M}_{\mathrm{n}+6}{ }^{*}\right)$.

Then one obtains a sorite whose LC is an "extension" of the above SOR2 LC:

$\mathrm{M}^{*}=\mathrm{M}^{*} \mathrm{~S} \mathrm{~S}^{* \prime} \mathrm{M}^{*} \mathrm{M}_{2}{ }^{* \prime} \mathrm{M}_{3}{ }^{* \prime} \ldots \mathrm{M}_{\mathrm{i}}^{* \prime} \mathrm{M}_{\mathrm{i}+1}{ }^{* \prime} \ldots \mathrm{M}_{\mathrm{n}}{ }^{*} \mathrm{P}{ }^{* \prime} \mathrm{M}_{\mathrm{n}+1}{ }^{* \prime} \mathrm{M}_{\mathrm{n}+2}{ }^{* \prime} \mathrm{M}_{\mathrm{n}+3}{ }^{* \prime} \mathrm{M}_{\mathrm{n}+4}{ }^{* \prime} \mathrm{M}_{\mathrm{n}+5}{ }^{* \prime} \mathrm{M}_{\mathrm{n}+6}{ }^{* \prime}$ Analogously, Darapti decorations of the same lengths as above may be added to a Daril type sorite, SOR3, via adding these premises:

$\mathrm{E}\left(\mathrm{S}^{* \prime}, \mathrm{M}_{\mathrm{n}+1}{ }^{*}\right) \mathrm{E}\left(\mathrm{M}_{1}{ }^{* \prime}, \mathrm{M}_{\mathrm{n}+2}{ }^{*}\right) \mathrm{E}\left(\mathrm{M}_{2}{ }^{* \prime}, \mathrm{M}_{\mathrm{n}+3}{ }^{*}\right) \mathrm{E}\left(\mathrm{M}_{2}{ }^{* \prime}, \mathrm{M}_{\mathrm{n}+4}{ }^{*}\right) \mathrm{E}\left(\mathrm{M}_{2}{ }^{* \prime}, \mathrm{M}_{\mathrm{n}+5}{ }^{*}\right) \mathrm{E}\left(\mathrm{P}^{* 1}, \mathrm{M}_{\mathrm{n}+6}{ }^{*}\right)$. 


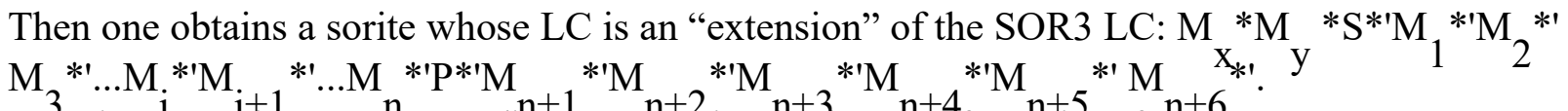
One thus sees that to any term/letter appearing in the $L$ e ${ }^{3}+4$ of a sorite of types 1,2 or 3 , one may add a "Darapti decoration", i.e., a (no matter how long) Darapti type sequence of premises with that letter as the "base", exactly as the term (or letter) M was the "base" of SOR2 - the Darapti type (2) sorite listed above.

If represented on a subsets' Karnaugh map with enough variables, the LC of the above SOR1, (resp. SOR2), say that $\mathrm{S}^{*}, \mathrm{P}^{*}$, (resp. $\mathrm{M}^{*}$ ), were reduced by the universal premises to just one, possibly not empty, partition subset of the universal set U. The LC of SOR3 affirms that just one partition subset of the universal set $U$ is not empty. (How to construct Karnaugh maps for any number of variables, starting from an $n=2$ Karnaugh map and then repeatedly using mirror images first towards the right, then towards the bottom of the page, is shown very clearly on Figures 3.1-3.4 at davidbonal.com.)

\section{About empty sets}

The above three types of VCA may also be used to settle which VCA are compatible with some of the sets $\mathrm{S}, \mathrm{P}, \mathrm{M}, \mathrm{S}^{\prime}, \mathrm{P}^{\prime}, \mathrm{M}^{\prime}$ being empty. In the modern square of opposition $\mathrm{A}(\mathrm{M}, \mathrm{P}), \mathrm{E}(\mathrm{M}, \mathrm{P})$ are not contraries anymore - unless one adds the condition $\mathrm{M} \neq \varnothing$. Instead when both $\mathrm{A}(\mathrm{M}, \mathrm{P}), \mathrm{E}(\mathrm{M}, \mathrm{P})$ are true it results that $\mathrm{M}=\varnothing$. This empty set constraint (ESC) - which empties all four subsets of M- is compatible with the universal premises of the VCA of type 1 and 2 - but not with the ei on M. Nor is the $\mathrm{M}=\varnothing$ ESC compatible with the type (3a) and $(3 \mathrm{~b})$ premises, $\mathrm{I}\left(\mathrm{S}^{*}, \mathrm{M}\right)$ and $\mathrm{I}\left(\mathrm{P}^{*}, \mathrm{M}\right)$. In fact, since the VCA of the same type are all equivalent, it results that a complete discussion of the compatibility of various ESCs and VCA may be reduced to examining just three or four representative cases:

Darii's PCP, A(M,P)I(S,M), means MP' $=\varnothing, \mathrm{SM} \neq \varnothing$, and the $\mathrm{LC}$ is $\mathrm{SM}=\mathrm{SMP}+\mathrm{SMP}{ }^{\prime}=\mathrm{SMP} \neq \varnothing$. From the LC SMP $\neq \varnothing$, one may, with some loss of information, eliminate $\mathrm{M}$, and re-express the $\mathrm{LC}$ as $\mathrm{I}(\mathrm{S}, \mathrm{P})=$ "Some $\mathrm{S}$ is $\mathrm{P}$ ". Thus the PCP is incompatible with the $\mathrm{S}=\varnothing, \mathrm{M}=\varnothing$, and $\mathrm{P}=\varnothing \mathrm{ESCs}$, but is compatible with the $\mathrm{S}^{\prime}=\mathrm{M}^{\prime}=\mathrm{P}^{\prime}=\varnothing \mathrm{ESCs}$, (which imply $\mathrm{S}=\mathrm{M}=\mathrm{P}=\mathrm{U}$; thus in this latter, extreme, case Darii's PCP and LC just affirm that $\mathrm{U}$ is non-empty).

Darapti's PCP, A(M,P)A(M,S), means $\mathrm{MP}^{\prime}=\varnothing, \mathrm{MS}^{\prime}=\varnothing$, and the $\mathrm{LC}$ is $\mathrm{M}=\mathrm{MP}+\mathrm{MP}{ }^{\prime}=\mathrm{MP}=$ MPS+MPS'=MPS, which may be written as A(M,SP). This time around one may eliminate $\mathrm{M}$ only via the ei hypothesis $\mathrm{M} \neq \varnothing$, then re-express the $\mathrm{LC}$ as $\mathrm{I}(\mathrm{S}, \mathrm{P})$. Thus the ei hypothesis is incompatible with the $\mathrm{M}=\varnothing, \mathrm{S}=\varnothing$ and $\mathrm{P}=\varnothing \mathrm{ESC}$, but is compatible with the $\mathrm{S}^{\prime}=\mathrm{M}^{\prime}=\mathrm{P}^{\prime}=\varnothing \mathrm{ESC}$, (which imply $\mathrm{S}=\mathrm{M}=\mathrm{P}=\mathrm{U}$; thus in this latter, extreme, case Darapti's PCP plus ei LC affirm that $\mathrm{U}$ is non-empty). Note that Darapti's PCP without the added ei condition is compatible even with $U=\varnothing$, in which case the PCP is just "chatter about empty sets".

Barbara's PCP, A(M,P)A(S,M), means MP' $=\varnothing, \mathrm{SM}^{\prime}=\varnothing$, and the $\mathrm{LCs}$ are $\mathrm{S}=\mathrm{SM}+\mathrm{SM}$ '=SM=SMP+ SMP'=SMP, and P'=P'M+ P'M'=P'M'= P'M'S+P'M'S'=P'M'S'. The first LC may be written as $\mathrm{A}(\mathrm{S}, \mathrm{MP})$, or, with some loss of information, one may eliminate $\mathrm{M}$, and write $\mathrm{A}(\mathrm{S}, \mathrm{P})=\mathrm{E}\left(\mathrm{S}, \mathrm{P}^{\prime}\right)$, which now refers to an entire column of $U$ instead of just one of the eight subsets of $U$. (A "precise" LC always pinpoints to just one of the eight subsets of U.) The second LC may be written as A(P', S'M'), or, with some loss of information, one may eliminate $\mathrm{M}^{\prime}$, and write $\mathrm{A}\left(\mathrm{P}^{\prime}, \mathrm{S}^{\prime}\right)=\mathrm{E}\left(\mathrm{S}, \mathrm{P}^{\prime}\right)$ - the same as the first LC. Since Barbara's PCP contains only universal premises, the PCP is compatible even with $\mathrm{U}=\varnothing$ in which case all the deductions and the LCs - either "precise" or "classically expressed", are just "chatter about empty sets". One may then add an ei hypothesis, $\mathrm{S} \neq \varnothing$, to the $1{ }^{\text {st }} \mathrm{LC}$, and a 
different ei hypothesis, $\mathrm{P}^{\prime} \neq \varnothing$, to the $2^{\text {nd }} \mathrm{LC}$, to obtain, after the $\mathrm{M}$, resp. M', elimination the new ei LCs: I(S,P), (Barbari), and resp., (the un-named), I(S',P'). The $S \neq \varnothing$ ei hypothesis means, since $\mathrm{S}=\mathrm{SPM}$, that also $\mathrm{P} \neq \varnothing$ and $\mathrm{M} \neq \varnothing$, while the compatible ESCs are $\mathrm{S}^{\prime}=\varnothing$, or/and, $\mathrm{P}^{\prime}=\varnothing$, or/and, $\mathrm{M}^{\prime}=\varnothing$. The $\mathrm{S}^{\prime}=\mathrm{P}^{\prime}=\mathrm{M}^{\prime}=\varnothing$ constraint amounts to Barbari affirming $\mathrm{U} \neq \varnothing$. The $\mathrm{P} \prime \neq \varnothing$ ei hypothesis means that also $S^{\prime} \neq \varnothing$ and $M^{\prime} \neq \varnothing$. If both ei hypotheses are true then all the sets $M, M^{\prime}, S, S^{\prime}, P, P^{\prime}$ are non-empty, and there are no ESCs compatible with both ei hypotheses.

In conclusion any universal premise is compatible with any ESC. But any ei hypothesis or any LC of a VCA of type (3), (containing one universal and one particular premise - both acting on either M or $\mathrm{M}^{\prime}$ ), specifies three sets that are non-empty, and thus pinpoints to three ESCs with which the ei hypothesis or the "type (3) LC" is incompatible.

\section{Inside each of the three types of VCA, any VCA can be re-written, without changing its PCP nor LC "content", as any other VCA of the same type}

One can define a "relabeling group" acting on each of the types (1), (2), (3a), and (3b) VCA sets. Let $\mathrm{p}:=\mathrm{P} \leftrightarrow \mathrm{P}^{\prime}, \mathrm{s}:=\mathrm{S} \leftrightarrow \mathrm{S}^{\prime}, \mathrm{m}:=\mathrm{M} \leftrightarrow \mathrm{M}^{\prime}$. One can see that compositions of $\mathrm{s}, \mathrm{p}, \mathrm{m}$ generate a commutative group $G$ with eight distinct elements:1,s,p,m,sp,sm,pm, spm. Obviously $1=\mathrm{s}^{2}=\mathrm{p}^{2}=\mathrm{m}^{2}=(\mathrm{spm})^{2}=$ $(\mathrm{ms})^{2}=(\mathrm{ps})^{2}=(\mathrm{pm})^{2}$. Each of the above 4 sets of VCAs of types (1), (2), (3a) and (3b) respectively, is invariant under the action of G. For example, the m relabeling transforms Barbara into a Barbara', (All $\mathrm{M}^{\prime}$ is $\mathrm{P}$, All S is $\mathrm{M}^{\prime}$, therefore $\mathrm{S}=\mathrm{SPM}$, etc.), and vice-versa, (and Darapti into a Darapti' and viceversa $), \mathrm{p}($ Celarent $/$ Cesare $)=$ Barbara, $\mathrm{m}($ Celarent/Cesare $)=($ Camestres/Camenes $)$, etc. (The prime added to the name of a VS shows that its LC refers to a subset of $\mathrm{M}^{\prime}$ as non-empty or possibly nonempty, while the LS of the same VS name without a prime refers to a corresponding subset of M: Barbara's LS is $\mathrm{S}=\mathrm{SPM}$, the LS of Barbara' is $\mathrm{S}=\mathrm{SPM}$, etc.) Since, via set relabelings, all variability inside each of the VCA sets (1), (2), (3a) and (3b) is accounted for, all the VCA from each set are logically equivalent. The $\mathrm{S} \leftrightarrow \mathrm{P}$ relabeling, when combined with the convention to firstly list the Ppremise, amounts to changing the premises' order. CCS uses it for syllogism reduction to the $1{ }^{\text {st }}$ figure; it transforms the type (3a) VCAs into type (3b) VCAs and vice versa. For example, $\operatorname{spm}\left(\mathrm{E}^{\prime} \mathrm{E}^{\prime}\right)=$ $\operatorname{spm}\left(\mathrm{E}\left(\mathrm{M}^{\prime}, \mathrm{P}\right) \mathrm{E}\left(\mathrm{M}^{\prime}, \mathrm{S}\right)\right)=\mathrm{E}\left(\mathrm{M}, \mathrm{P}^{\prime}\right) \mathrm{E}\left(\mathrm{M}, \mathrm{S}^{\prime}\right)=\mathrm{A}(\mathrm{M}, \mathrm{P}) \mathrm{A}(\mathrm{M}, \mathrm{S})=\mathrm{AA}$ which are Darapti's premises with the LC M=MSP. This means that $E^{\prime} E^{\prime}=E\left(M^{\prime}, P\right) E\left(M^{\prime}, S\right)=A(P, M) A(S, M)$ become Darapti's premises after an spm relabeling. Equivalently one may read $\mathrm{E}^{\prime} \mathrm{E}^{\prime}$, i.e., All $\mathrm{P}$ is $\mathrm{M}$, All S is $\mathrm{M}$, as All non $\mathrm{P}^{\prime}$ is non $\mathrm{M}^{\prime}$, All non $S^{\prime}$ is non $M^{\prime}$ which by contraposition means $A l l M^{\prime}$ is $P^{\prime}, A l l ~ M^{\prime}$ is $S^{\prime}$, which now reads like a Darapti in the variables $\mathrm{M}^{\prime}, \mathrm{P}^{\prime}, \mathrm{S}^{\prime}$, with the LC M'=M'S'P', which is still the LC of $\mathrm{E}^{\prime} \mathrm{E}^{\prime}$. The 32, (out of the distinct 64), PCPs which entail at least one LC per PCP, were classified as being of types (1), (2), (3a), and (3b) - each of the these types containing 8 PCPs. One may arrange these 32 PCPs into 8 sets of four PCPs each, such that the variables in each set are (almost) the same. One can denote these four set PCPs from 1 to 8 , and one can let the relabeling group $\mathrm{G}$ act on these eight sets of four PCPs each. Below, the first PCP in such a set of four PCPs always belongs to type (2) PCP, the following two belong to type (3a) and (3b) PCP and the last one to type (1) PCP - this latter PCP entails two LCs and thus generates two VCAs, from which two ei VCAs can further be inferred. (This is how one gets to the total count of 64 VCAs and ei VCAs.) We'll say that each of such a four PCPs set is "bound to" a same subset of $U$ : the four PCPs do not act at all on the subset of $U$ on which they are all "bound", but act on some of its "neighbours" in the Karnaugh map. Thus to each of the 8 subsets of U one 
"attaches" a set of four PCPs "bound" to it. Listing on one column the four PCPs, and on the second column their LCs, these eight sets of PCPs and LCs are:

1. VCAs "bound to" the subset S'P'M:
$\mathrm{EE}=\mathrm{E}(\mathrm{M}, \mathrm{P}) \mathrm{E}(\mathrm{M}, \mathrm{S})$
$\mathrm{IE}=\mathrm{I}(\mathrm{M}, \mathrm{P}) \mathrm{E}(\mathrm{M}, \mathrm{S})$
$\mathrm{M}=\mathrm{S}^{\prime} \mathrm{P} ' \mathrm{M}$. If $\mathrm{M} \neq \varnothing$ : I( $\left.\mathrm{S}^{\prime}, \mathrm{P}^{\prime}\right)$, No name
$\mathrm{S}^{\prime} \mathrm{PM} \neq \varnothing$ or $\mathrm{O}(\mathrm{P}, \mathrm{S})$, No name
$\mathrm{SP}^{\prime} \mathrm{M} \neq \varnothing$ or $\mathrm{O}(\mathrm{S}, \mathrm{P})$, Ferio/Festino/Ferison/Fresison
$\mathrm{EI}=\mathrm{E}(\mathrm{M}, \mathrm{P}) \mathrm{I}(\mathrm{M}, \mathrm{S})$
$\mathrm{EE} \mathrm{E}^{\prime}=\mathrm{E}(\mathrm{M}, \mathrm{P}) \mathrm{E}\left(\mathrm{M}^{\prime}, \mathrm{S}\right)$
$\mathrm{S}=\mathrm{SP}$ M, $\mathrm{P}=\mathrm{S}^{\prime} \mathrm{PM}$, E(S,P), Celarent/Cesare
$\mathrm{O}(\mathrm{S}, \mathrm{P})$ if $\mathrm{S} \neq \varnothing$, Celaront/Cesaro; $\mathrm{O}(\mathrm{P}, \mathrm{S})$ if $\mathrm{P} \neq \varnothing$, No name

2. VCAs bound to the subset SP'M:
$\mathrm{EA}=\mathrm{E}(\mathrm{M}, \mathrm{P}) \mathrm{E}\left(\mathrm{M}, \mathrm{S}^{\prime}\right)$
$\mathrm{IA}=\mathrm{I}(\mathrm{M}, \mathrm{P}) \mathrm{E}\left(\mathrm{M}, \mathrm{S}^{\prime}\right)$
$\mathrm{EO}=\mathrm{E}(\mathrm{M}, \mathrm{P}) \mathrm{I}\left(\mathrm{M}, \mathrm{S}^{\prime}\right)$
$\mathrm{EA}^{\prime}=\mathrm{E}(\mathrm{M}, \mathrm{P}) \mathrm{E}\left(\mathrm{M}^{\prime}, \mathrm{S}^{\prime}\right)$

$\mathrm{M}=\mathrm{SP} M$. If $\mathrm{M} \neq \varnothing: \mathrm{O}(\mathrm{S}, \mathrm{P})$, Felapton/Fesapo

$\mathrm{SPM} \neq \varnothing$ or I(S,P), Disamis/Dimaris

$\mathrm{S}^{\prime} \mathrm{P}^{\prime} \mathrm{M} \neq \varnothing$ or $\mathrm{I}\left(\mathrm{S}^{\prime}, \mathrm{P}^{\prime}\right)$, No name

$\mathrm{P}=\mathrm{SPM} \mathrm{M}^{\prime}, \mathrm{S}^{\prime}=\mathrm{S}^{\prime} \mathrm{P} \mathrm{M}, \mathrm{A}(\mathrm{P}, \mathrm{S})=\mathrm{A}\left(\mathrm{S}^{\prime}, \mathrm{P}^{\prime}\right)$,

$\mathrm{I}(\mathrm{S}, \mathrm{P})$ if $\mathrm{P} \neq \varnothing$, Bramantip' (the prime refers to $\mathrm{M}^{\prime}$ in

$\left.\mathrm{P}=\mathrm{SPM} \mathrm{M}^{\prime}\right)$; $\mathrm{I}\left(\mathrm{S}^{\prime}, \mathrm{P}^{\prime}\right)$ if $\mathrm{S}^{\prime} \neq \varnothing$, No name

3. VCAs bound to the subset $\mathrm{S}^{\prime} \mathrm{PM}$ :
$\mathrm{AE}=\mathrm{E}\left(\mathrm{M}, \mathrm{P}^{\prime}\right) \mathrm{E}(\mathrm{M}, \mathrm{S})$
$\mathrm{OE}=\mathrm{I}\left(\mathrm{M}, \mathrm{P}^{\prime}\right) \mathrm{E}(\mathrm{M}, \mathrm{S})$
$\mathrm{AI}=\mathrm{E}\left(\mathrm{M}, \mathrm{P}^{\prime}\right) \mathrm{I}(\mathrm{M}, \mathrm{S})$
$\mathrm{AE}^{\prime}=\mathrm{E}\left(\mathrm{M}, \mathrm{P}^{\prime}\right) \mathrm{E}\left(\mathrm{M}^{\prime}, \mathrm{S}\right)$
$\mathrm{M}=\mathrm{S}{ }^{\prime} \mathrm{PM}$. If $\mathrm{M} \neq \varnothing: \mathrm{O}(\mathrm{P}, \mathrm{S})$, No name
$\mathrm{S}^{\prime} \mathrm{P}^{\prime} \mathrm{M} \neq \varnothing$ or $\mathrm{I}\left(\mathrm{S}^{\prime}, \mathrm{P}^{\prime}\right)$, No name
$\mathrm{SPM} \neq \varnothing$ or I(S,P), Darii/Datisi
$\mathrm{S}=\mathrm{SPM}, \mathrm{P}^{\prime}=\mathrm{S}^{\prime} \mathrm{P}^{\prime} \mathrm{M}^{\prime}, \mathrm{A}(\mathrm{S}, \mathrm{P})$, Barbara
$\mathrm{I}(\mathrm{S}, \mathrm{P})$ if $\mathrm{S} \neq \varnothing$, Barbari; $\mathrm{I}\left(\mathrm{S}^{\prime}, \mathrm{P}^{\prime}\right)$ if $\mathrm{P}^{\prime} \neq \varnothing$, No name

4. VCAs bound to the subset SPM:
$\mathrm{AA}=\mathrm{E}\left(\mathrm{M}, \mathrm{P}^{\prime}\right) \mathrm{E}\left(\mathrm{M}, \mathrm{S}^{\prime}\right)$
$\mathrm{OA}=\mathrm{I}\left(\mathrm{M}, \mathrm{P}^{\prime}\right) \mathrm{E}\left(\mathrm{M}, \mathrm{S}^{\prime}\right)$
$\mathrm{AO}=\mathrm{E}\left(\mathrm{M}, \mathrm{P}^{\prime}\right) \mathrm{I}\left(\mathrm{M}, \mathrm{S}^{\prime}\right)$
$\mathrm{M}=\mathrm{SPM}$. If $\mathrm{M} \neq \varnothing$ : I(S,P), Darapti
$\mathrm{SP}^{\prime} \mathrm{M} \neq \varnothing$ or $\mathrm{O}(\mathrm{S}, \mathrm{P})$, Bocardo
$\mathrm{S}^{\prime} \mathrm{PM} \neq \varnothing$ or $\mathrm{O}(\mathrm{P}, \mathrm{S})$, No name
$\mathrm{AA}^{\prime}=\mathrm{E}\left(\mathrm{M}, \mathrm{P}^{\prime}\right) \mathrm{E}\left(\mathrm{M}^{\prime}, \mathrm{S}^{\prime}\right)$
$\mathrm{S}^{\prime}=\mathrm{S}^{\prime} \mathrm{PM}, \mathrm{P}^{\prime}=\mathrm{SP}^{\prime} \mathrm{M}^{\prime}, \mathrm{E}\left(\mathrm{S}^{\prime}, \mathrm{P}^{\prime}\right)$, No name
$\mathrm{O}(\mathrm{P}, \mathrm{S})$ if $\mathrm{S}^{\prime} \neq \varnothing$, No name; $\mathrm{O}(\mathrm{S}, \mathrm{P})$ if $\mathrm{P}^{\prime} \neq \varnothing$, No name

M' row VCAs:

5. VCAs bound to the subset $\mathrm{S}^{\prime} \mathrm{P}^{\prime} \mathrm{M}^{\prime}$ :

$\mathrm{E}^{\prime} \mathrm{E}^{\prime}=\mathrm{E}\left(\mathrm{M}^{\prime}, \mathrm{P}\right) \mathrm{E}\left(\mathrm{M}^{\prime}, \mathrm{S}\right)$

$I^{\prime} E^{\prime}=I\left(M^{\prime}, P\right) E\left(M^{\prime}, S\right)$

$E^{\prime} I^{\prime}=E\left(M^{\prime}, P\right) I\left(M^{\prime}, S\right)$

$\mathrm{E}^{\prime} \mathrm{E}=\mathrm{E}\left(\mathrm{M}^{\prime}, \mathrm{P}\right) \mathrm{E}(\mathrm{M}, \mathrm{S})$
$M^{\prime}=S^{\prime} P^{\prime} M^{\prime}$. If $M^{\prime} \neq \varnothing: I\left(S^{\prime}, P^{\prime}\right)$, No name

$\mathrm{S}^{\prime} \mathrm{PM} \neq \varnothing$ or $\mathrm{O}(\mathrm{P}, \mathrm{S})$, No name

$\mathrm{SP}^{\prime} \mathrm{M}^{\prime} \neq \varnothing$ or $\mathrm{O}(\mathrm{S}, \mathrm{P})$, Baroco

$\mathrm{S}=\mathrm{SP}$ 'M', P=S'PM, E(S,P), Camestres/Camenes

$\mathrm{O}(\mathrm{S}, \mathrm{P})$ if $\mathrm{S} \neq \varnothing$, Camestros/Camenos; $\mathrm{O}(\mathrm{P}, \mathrm{S})$ if $\mathrm{P} \neq \varnothing$, No name

6. VCAs bound to the subset SP'M':

$E^{\prime} A^{\prime}=E\left(M^{\prime}, P\right) E\left(M^{\prime}, S^{\prime}\right)$
$I^{\prime} A^{\prime}=I\left(M^{\prime}, P\right) E\left(M^{\prime}, S^{\prime}\right)$
$E^{\prime} O^{\prime}=E\left(M^{\prime}, P\right) I\left(M^{\prime}, S^{\prime}\right)$
$E^{\prime} A=E\left(M^{\prime}, P\right) E\left(M, S^{\prime}\right)$

$\mathrm{M}^{\prime}=\mathrm{SP}^{\prime} \mathrm{M}^{\prime}$. If $\mathrm{M}^{\prime} \neq \varnothing: \mathrm{O}(\mathrm{S}, \mathrm{P})$, Felapton'/Fesapo'

$\mathrm{SPM}^{\prime} \neq \varnothing$ or I(S,P), Disamis'/Dimaris'

$\mathrm{S}^{\prime} \mathrm{P}^{\prime} \mathrm{M} \neq \varnothing$ or $\mathrm{I}\left(\mathrm{S}^{\prime}, \mathrm{P}^{\prime}\right)$, No name

$\mathrm{S}^{\prime}=\mathrm{S}^{\prime} \mathrm{P} \mathrm{M}^{\prime}, \mathrm{P}=\mathrm{SPM}, \mathrm{E}\left(\mathrm{S}^{\prime}, \mathrm{P}\right)=\mathrm{A}(\mathrm{P}, \mathrm{S})$, No name

$\mathrm{I}(\mathrm{S}, \mathrm{P})$ if $\mathrm{P} \neq \varnothing$, Bramantip, I( $\left.\mathrm{S}^{\prime}, \mathrm{P}^{\prime}\right)$ if $\mathrm{S}^{\prime} \neq \varnothing$, No name 
7. VCAs bound to the subset S'PM':
$\mathrm{A}^{\prime} \mathrm{E}^{\prime}=\mathrm{E}\left(\mathrm{M}^{\prime}, \mathrm{P}^{\prime}\right) \mathrm{E}\left(\mathrm{M}^{\prime}, \mathrm{S}\right)$
$\mathrm{M}^{\prime}=\mathrm{S}^{\prime} \mathrm{P} \mathrm{M}^{\prime}$. If $\mathrm{M}^{\prime} \neq \varnothing: \mathrm{O}(\mathrm{P}, \mathrm{S})$, No name
$\mathrm{O}^{\prime} \mathrm{E}^{\prime}=\mathrm{I}\left(\mathrm{M}^{\prime}, \mathrm{P}^{\prime}\right) \mathrm{E}\left(\mathrm{M}^{\prime}, \mathrm{S}\right)$
$\mathrm{S}^{\prime} \mathrm{P}^{\prime} \mathrm{M}^{\prime} \neq \varnothing$ or $\mathrm{I}\left(\mathrm{S}^{\prime}, \mathrm{P}^{\prime}\right)$, No name
$\mathrm{A}^{\prime} \mathrm{I}^{\prime}=\mathrm{E}\left(\mathrm{M}^{\prime}, \mathrm{P}^{\prime}\right) \mathrm{I}\left(\mathrm{M}^{\prime}, \mathrm{S}\right)$
$\mathrm{SPM}^{\prime} \neq \varnothing$ or I(S,P), Darii'/Datisi'
$\mathrm{A}^{\prime} \mathrm{E}=\mathrm{E}\left(\mathrm{M}^{\prime}, \mathrm{P}^{\prime}\right) \mathrm{E}(\mathrm{M}, \mathrm{S})$
$\mathrm{S}=\mathrm{SPM}, \mathrm{P}^{\prime}=\mathrm{S}^{\prime} \mathrm{P}^{\prime} \mathrm{M}, \mathrm{A}(\mathrm{S}, \mathrm{P})=\mathrm{A}\left(\mathrm{P}^{\prime}, \mathrm{S}^{\prime}\right)$, Barbara'
$\mathrm{I}(\mathrm{S}, \mathrm{P})$ if $\mathrm{S} \neq \varnothing$, Barbari'; $\mathrm{I}\left(\mathrm{S}^{\prime}, \mathrm{P}^{\prime}\right)$ if $\mathrm{P}^{\prime} \neq \varnothing$, No name

8. VCAs bound to the subset SPM':
$\mathrm{A}^{\prime} \mathrm{A}^{\prime}=\mathrm{E}\left(\mathrm{M}^{\prime}, \mathrm{P}^{\prime}\right) \mathrm{E}\left(\mathrm{M}^{\prime}, \mathrm{S}^{\prime}\right)$
$\mathrm{M}^{\prime}=\mathrm{SPM}^{\prime}$. If $\mathrm{M}^{\prime} \neq \varnothing: \mathrm{I}(\mathrm{S}, \mathrm{P})$, Darapti'
$\mathrm{O}^{\prime} \mathrm{A}^{\prime}=\mathrm{I}\left(\mathrm{M}^{\prime}, \mathrm{P}^{\prime}\right) \mathrm{E}\left(\mathrm{M}^{\prime}, \mathrm{S}^{\prime}\right)$
$\mathrm{SP}^{\prime} \mathrm{M}^{\prime} \neq \varnothing$ or $\mathrm{O}(\mathrm{S}, \mathrm{P})$, Bocardo'
$\mathrm{A}^{\prime} \mathrm{O}^{\prime}=\mathrm{E}\left(\mathrm{M}^{\prime}, \mathrm{P}^{\prime}\right) \mathrm{I}\left(\mathrm{M}^{\prime}, \mathrm{S}^{\prime}\right)$
$\mathrm{S}^{\prime} \mathrm{PM} \neq \varnothing$ or $\mathrm{O}(\mathrm{P}, \mathrm{S})$, No name
$\mathrm{A}^{\prime} \mathrm{A}=\mathrm{E}\left(\mathrm{M}^{\prime}, \mathrm{P}^{\prime}\right) \mathrm{E}\left(\mathrm{M}, \mathrm{S}^{\prime}\right)$
$\mathrm{S}^{\prime}=\mathrm{S}^{\prime} \mathrm{PM} \mathrm{M}^{\prime}, \mathrm{P}^{\prime}=\mathrm{SP} \mathrm{P}^{\prime} \mathrm{M}, \mathrm{E}\left(\mathrm{S}^{\prime}, \mathrm{P}^{\prime}\right)$, No name
$\mathrm{O}(\mathrm{P}, \mathrm{S})$ if $\mathrm{S}^{\prime} \neq \varnothing$, No name; $\mathrm{O}(\mathrm{S}, \mathrm{P})$ if $\mathrm{P}^{\prime} \neq \varnothing$, No name

One can check that the group $\mathrm{G}$ acts on the above PCPs and LCs sets, denoted $1,2, \ldots, 8$, as follows: $\mathrm{p}(1)=3, \mathrm{p}(2)=4, \mathrm{p}(5)=7, \mathrm{p}(6)=8 ; \mathrm{s}(1)=2, \mathrm{~s}(3)=4, \mathrm{~s}(5)=6, \mathrm{~s}(7)=8 ; \mathrm{m}(1)=5, \mathrm{~m}(2)=6$, $\mathrm{m}(3)=7, \mathrm{~m}(4)=8$.

One can also check that $\{\mathrm{G}(1)\}=\{\mathrm{G}(2)\}=\ldots=\{\mathrm{G}(8)\}=\{1,2,3, \ldots, 8\}$. This shows that any VCA from any of the four VCA (sub)types can be recast as any other VCA of the same (sub)type. (A change of the order of premises, together with the convention of firstly listing the P-premise, completes the transformation of a subtype (3a) VCA into a subtype (3b) VCA and vice versa.)

\section{Conclusions}

The set model shows very intuitively what an LC is, and what a lack of LC means. For each of the three types of PCP entailing at least one LC, the pointing to a unique subset of $U$ is key: if a PCP singles out one of the 8 subsets of $\mathrm{U}$, then one has an LC - if not, there is no LC.

STM proves a generalized form of RofVS \#3: that in a VCA, any of the end terms, S, S',P,P', is distributed in a premise if and only if it is distributed in the LC, unless ei is imposed on that term, in which case the term was distributed in its premise and is undistributed in the LC. STM also proves a generalized form of RofVS \#4: in any VCA, either two affirmative, or two negative premises entail an affirmative LC; if the PCP contains only one negative premise, then the $\mathrm{LC}$ is also negative. For classification purposes, the P-premise is listed firstly in both STM and the CCS. The latter recognizes two equivalence classes of VCAs: the VS having $\mathrm{A}(\mathrm{S}, \mathrm{P})$ or $\mathrm{O}(\mathrm{S}, \mathrm{P})$ statements as LCs, and the VCA with $\mathrm{A}(\mathrm{P}, \mathrm{S})$ or $\mathrm{O}(\mathrm{P}, \mathrm{S}) \mathrm{LCs}$ : the VCA from one class are transformed into the other class VCA via a relabeling $\mathrm{S} \leftrightarrow \mathrm{P}$ and a switch of the premises' order. This equivalence is taken as a sign that the VCA from the second class may be discarded since they can be recasted as VS. Thus the VCAs whose LCs are A(P,S) or O(P,S) statements are weeded out by the very definition of a VS, not by RofVS, which the discarded VCAs still fully satisfy. Note though that the same $\mathrm{S} \leftrightarrow \mathrm{P}$ relabeling and a switch of the premises' order, transforms Camestres/ Camenes into Celarent/ Cesare, but nevertheless neither Camestres/ Camenes nor Celarent/Cesare are discarded since both have as LC the E(S,P)= $\mathrm{E}(\mathrm{P}, \mathrm{S})$ statement in which either term may be used as the predicate. This may suggest that the first two RofVS are rather ad hoc rules meant to weed out VCA containing negative terms in the PCP, or the LC. The STM recognizes two similar equivalence classes of VCAs - namely the type (3a) and type (3b) VCAs are equivalent via the switch of the premises' order combined with the relabeling $\mathrm{S} \leftrightarrow \mathrm{P}$, aka following the convention that the firstly listed premise contains the P term. Moreover the VCAs 
from the same (sub)type (1), (2), (3a) and (3b) are equivalent via a relabeling from the 8-element group $\mathrm{G}$ generated by the $\mathrm{p}:=\mathrm{P} \leftrightarrow \mathrm{P}^{\prime}, \mathrm{s}:=\mathrm{S} \leftrightarrow \mathrm{S}^{\prime}$, and $\mathrm{m}:=\mathrm{M} \leftrightarrow \mathrm{M}^{\prime}$ relabelings. Generalizing from VS to VCA and from 36 PCPs to 64, one discovers that modulo a term relabeling and a switch of the premises' order, there are only three distinct VCA and/or VS - one per each of the three PCP types discovered by George Boole and Lewis Carroll.

For newer takes on categorical syllogisms one may read, e.g., Frank Thomas Sautter, (2019), or Stephen Read, (2017). But the Boole and Carroll "three VCA types approach" so clearly displays the structure of any VCA, that finally, I think, the 'Logicians', should relent, and teach it to every logic student, while taking away the center stage from the VS moods and figures, and the first two RofVS.

\section{Bibliography}

Boole, George (1847). The mathematical analysis of logic, being an essay towards a calculus of deductive reasoning (31-41). Cambridge University Press. ISBN: 9781108001014.

Carroll, Lewis Symbolic Logic. Part I Elementary, 1896. Fifth Edition. Part II, Advanced, never previously published. Edited, with annotations and an introduction, by William Warren Bartley, III (119-132, 240, 250). Publisher: Clarkson Potter; Reprint edition (June 11, 1986). ISBN: 0517533634.

Carroll, Lewis Symbolic Logic. Part I Elementary (73-84, 173). Forth Edition. Dover edition, 1958. ISBN: 0486204928.

Copi, Irving M., Cohen, Carl Introduction to Logic (240-248). 13th edition, 2009. ISBN: 0136000983.

Hurley, Patrick J. A Concise Introduction to Logic (272-280, 285-291). Cengage Learning 12th edition, 2015. ISBN: 1285196546.

Karnaugh, Maurice (1953), The map method for synthesis of combinational logic circuits. Transactions of the American Institute of Electrical Engineers, Part 1, (72), 593-599. doi: 10.1109/TCE.1953.6371932.

Keynes, John Neville (1987) Studies and Exercises in Formal Logic (68, 172-194).

Available at: https://archive.org/details/studiesandexerci029427mbp/page/n6

Marquand, Allan (1881), On logical diagrams for $n$ terms, Philosophical Magazine (12), 266-270. doi: 10.1080/14786448108627104.

Quine, Willard Van Orman Methods of Logic (98-108). Harvard Univsity Press $4^{\text {th }}$ edition (1982). ISBN: 0674571762.

Read, Stephen (2017). Aristotle's Theory of the Assertoric Syllogism, Available at: https://philarchive.org/rec/REAATO-5.

Sautter, Frank Thomas (2019). A Bunch of Diagrammatic Methods for Syllogistic, Logica Universalis (13), 21-36. doi: 10.1007/s11787-019-00220-6.

Stebbing, L. Susan (1961). A Modern Introduction to Logic Harper \& Row (86-92). ASIN: B002VYAKK8.

Striker, Gisela (2009) Aristotle's Prior Analytics Book I, 20. Oxford University Press. ISBN: 0199250405.

Veitch, Edward, W. (1952). A chart method for simplifying truth functions, 127-133. Proceedings of the Association for Computing Machinery. doi: 10.1145/609784.609801

Venn, John (1880). On the Diagrammatic and Mechanical Representation of Propositions and Reasonings. The London, Edinburgh, and Dublin Philosophical Magazine and Journal of Science. Series 5, Vol 9 (No. 59), 1-18. doi:10.1080/14786448008626877. 